\title{
Analysis of bond-slip between concrete and steel bar in fire
}

\author{
Jamal Khalaf, Zhaohui Huang* and Mizi Fan \\ Department of Mechanical, Aerospace and Civil Engineering \\ College of Engineering, Design and Physical Science, Brunel University, Uxbridge, \\ Middlesex UB8 3PH, UK
}

\begin{abstract}
This paper presents a robust model for predicting the bond-slip between the concrete and steel reinforced bar at elevated temperatures. The model is established based on a partly cracked thick-wall cylinder theory and the smeared cracking approach is adopted to consider the softening behaviour of concrete in tension. The model is able to consider a number of parameters: such as different concrete properties and covers; different steel bar diameters and geometries. The proposed model has been incorporated into the Vulcan program for 3D analysis of reinforced concrete structures in fire. The model has been validated against previous test results.
\end{abstract}

KEYWORDS: Bond-slip, concrete structures, fire, splitting failure.

\section{RESEARCH HIGHLIGHTS:}

Develop a robust model for predicting the bond-slip between the concrete and steel reinforced bar at elevated temperatures.

$>$ Incorporate the bond-slip model into the Vulcan program for 3D analysis of reinforced concrete structures in fire.

$>$ The model has been validated against previous test results and good agreements are achieved.

* Corresponding author:

E-mail address: zhaohui.huang@ brunel.ac.uk (Z. Huang). 


\section{NOTATION}

The following symbols are used in this paper:

$\sigma_{r} \quad$ radial stress

$\sigma_{t, T} \quad$ tangential stress at elevated temperatures

$P_{T}^{i} \quad$ total radial pressure at elevated temperatures

$P_{i, T} \quad$ pressure resistance of the elastic outer zone at elevated temperatures

$r \quad$ radius from the centre of the rebar

$R_{s} \quad$ radius of the steel bar

$R_{c} \quad$ radius of concrete cylinder $=R_{s}+$ the least thickness of concrete cover

$R_{i} \quad$ radius of the uncracked inner face

$\varepsilon_{u, T} \quad$ smeared strain of concrete at elevated temperatures when tensile stress equal to zero

$\varepsilon_{t, 0} \quad$ smeared tangential strain at the rebar interface

$f_{c t} \quad$ tensile strength of concrete at ambient temperature

$E_{0, T}$ initial elastic modulus of concrete at elevated temperatures

$\tau_{T}^{i} \quad$ bond stress at elevated temperatures

$\alpha \quad$ effective face angle

$f_{c t, T}$ degradation of the concrete tensile strength at elevated temperatures

C concrete cover

$S_{\max }$ maximum slip at the maximum bond stress point $\tau_{\max }$

$F_{T, x}^{i} \quad$ bonding force between the concrete and the steel bar

$A$ the contact area between the concrete and the reinforcing steel bar

$U$ perimeter of the steel bar

$L \quad$ length of the steel bar which contributes to the node connected by the bond element

$\Delta \mathbf{F}$ nodal force increment vector

$\Delta \mathbf{u}$ nodal displacement increment vector

$k_{1}^{i} \quad$ tangent stiffness coefficients of the bond connector

$l_{b} \quad$ embedded length of the rebar inside the specimens

$d_{b} \quad$ diameter of the rebar 


\section{Introduction}

Exposure of concrete structures to high temperatures leads to significant losses in mechanical and physical properties of concrete and steel reinforcement as well as the bond characteristics between them. Degradation of bond properties in fire may significantly influence the load capacity or flexibility of the concrete structures. Therefore the bond behaviours need to be considered for the structural fire engineering design of reinforced concrete structures. At present, the information about the material degradations of concrete and reinforcing steel bars at elevated temperatures are generally available. However, the research on the response of the bond characteristic between concrete and reinforcing steel bar at elevated temperatures is still limited $[1,2]$.

Previous researchers indicated that when the reinforced concrete members are loaded, the stresses in the interface between concrete and steel bar increase. The capacity of the interface to transmit stress starts to deteriorate at the particular load level, and this deterioration becomes worse at elevated temperatures. The damage at the interface of the bond gradually spreads to the surrounding concretes. The development of this process results in a slip between the steel and concrete. The mechanism to transfer stresses between concrete and rebar can be represented by adhesion, mechanical interlock and friction. Adhesion can be defined as the chemical bonds which are developed during the curing process of concrete. This bond is very small and can be lost in the early stages of loading or during exposure to fire. Hence, this kind of the bond can be ignored in the modelling of bond characteristics in fire. In the case when deformed bars are used, stresses are transferred mainly by mechanical interaction between the rebar's ribs and the adjacent concretes. Also, the friction does not occur until there is a slip between the steel bars and concrete [3-6].

For the mechanical interaction of the bond, there are two types of bond failure which can take place. The first one is pull out failure (shear off) due to the cover of concrete is very large and under high confinement. In this case, concretes are shearing off by the wedging action of ribs, and then concretes between the ribs are crushed gradually resulting in a pull-out failure. The second type of failure is splitting failure due to the cracks of the concrete cover surrounding the steel bar start to propagate radially. This type of failure is more common for pull-out tests of reinforced steel bars in the real structures [2-4].

During the past decades, numerous models have been developed to calculate bond stress at ambient temperature [3-8]. The majority of these models is empirical and based on a 
statistical methodology. Thus, these models are highly dependent on the test data, which may limit their validity in the different situations [3]. Currently there are a limited number of numerical models available for modelling bond characteristics at elevated temperatures. Huang [9] adopted the CEB-FIP bond-slip model at ambient temperature [10] and considered the degradation of bond strength at elevated temperatures by using the experimental results generated by Bazant and Kaplan [11]. Hence, the Huang's model is the first order approximation of the bond characteristics in fire. Pothisiri and Panedpojaman [2] have proposed a mechanical bond-slip model at elevated temperatures based on the theory of thick-wall cylinder and smeared crack of concrete in tension. The model has taken into account the variation of concrete properties with temperatures and the differential thermal expansion of rebar and concrete. However, the model was established to calculate the bondslip based on the correlation between the experimental slip obtained from previous researches.

As indicated in Reference [9], due to the lack of robust models for considering the influence of the bond characteristics between the concrete and steel bar at elevated temperatures, the majority of the numerical models developed for predicting the behaviour of reinforced concrete structures in fire was based on the full bond interaction. Hence, the main objective of this paper is to develop a robust numerical model for predicting the bond-slip between concrete and steel bar under fire conditions. The model presented in this paper is mainly based on the partly cracked thick-wall cylinder theory and the smeared cracking approach is adopted to simulate the splitting failure of the concrete cover. In this numerical model, the calculation of the bond slip relationship is based on the constitutive equations of concrete and geometric properties of the rebar and concrete cover. The developed mode can generate the bond stress-slip curve at elevated temperatures. The model can be used to calculate the bond radial pressure, bond stress versus slip. Also, this numerical model has been incorporated into the Vulcan software [12] for 3D modelling reinforced concrete structures under fire conditions.

\section{Analytical model}

The mechanical action between the rebar's ribs and the surrounding concretes is explained in Fig. 1. The transfer of the load between the reinforced bar and concrete is achieved by the bearing of the ribs on the concrete. The resultant forces acting on the ribs are compressive forces which are generated due to the restraint of the surrounding concrete. The compressive 
forces acting on the ribs resulted from the pull out load are decomposed into two directions, parallel and perpendicular to the reinforced steel bar. The reaction forces acting on the concrete, due to the perpendicular components of the compressive forces acting on the ribs, create circumferential tension stresses in the concretes surrounding the steel bar. If these tensile stresses exceed the tensile strength of concrete, splitting failure occurs [5]. Wang and Liu [5] have established a model based on the theory of thick wall cylinder [4] by taking into account the strain-softening of concrete in tension to calculate the maximum radial stress and maximum bond stress.

As mentioned above the bond-slip model developed in this paper is mainly based on the partly cracked thick-wall cylinder theory with the aid of a smeared cracking approach and average stress-strain of concrete in tension $[4,5]$. As shown in Fig. 2, the magnitude of the pressure acting on the steel rebar, $P_{T}^{i}$, increases when pull-out force acting on the rebar increases. When $P_{T}^{i}$ reaches to the maximum value, which is the capacity of the bond, then the bond will fail and $P_{T}^{i}$ starts to reduce with increasing bond slip until $R_{i}$ reaching to $R_{c}$, in which $R_{i}$ is radius of the uncracked inner face and $R_{c}$ is the radius of concrete cover (see Fig. 2).

In the partly cracked thick-wall cylinder theory there are three stages: the first stage is the uncracked stage; the second stage is the partly cracked stage and the third stage is the entirely cracked stage $[4,6]$.

\section{Uncracked stage:}

As shown in Fig. 2a, for uncracked outer part of the concrete cover, the linear elastic behaviour of the concrete cylinder is assumed. Based on the theory of elasticity the pressure at inner surface of uncracked outer part $P_{i, T}$, compressive radial stress $\sigma_{r}$ and the tensile tangential stress $\sigma_{t, T}$ are represented as [13]:

$$
\begin{gathered}
\sigma_{r}=\frac{R_{i}^{2} P_{i, T}}{R_{c}^{2}-R_{i}^{2}}\left[1-\frac{R_{c}^{2}}{r^{2}}\right] \\
\sigma_{t, T}=\frac{R_{i}^{2} P_{i, T}}{R_{c}^{2}-R_{i}^{2}}\left[1+\frac{R_{c}^{2}}{r^{2}}\right]
\end{gathered}
$$


For uncracked outer part of the concrete cover the tensile stress $\sigma_{t, T}$ cannot exceed the tensile strength of concrete at elevated temperatures $f_{c t, T}$. According to Eq. (2), $P_{i, T}$ is calculated as:

$$
P_{i, T}=f_{c t, T} \frac{R_{c}^{2}-R_{i}^{2}}{R_{c}^{2}+R_{i}^{2}}
$$

As shown in Fig. 3, at uncracked stage $\left(R_{i}=R_{s}\right) P_{i, T}=P_{0, T}=f_{c t, T} \frac{R_{c}^{2}-R_{s}^{2}}{R_{c}^{2}+R_{s}^{2}}$.

\section{Partly cracked stage:}

In this stage the concrete cylinder is subdivided into an uncracked outer part and cracked inner part, as shown in Fig. 2. The contribution of the uncracked outer part to the radial stress at the interface between concrete and steel bar at temperature $T, P_{0, T}^{i}$ is represented as:

$$
P_{0, T}^{i}=\frac{R_{i}}{R_{s}} P_{i, T}=\frac{R_{i}}{R_{s}}\left[f_{c t, T} \frac{R_{c}^{2}-R_{i}^{2}}{R_{c}^{2}+R_{i}^{2}}\right]
$$

In this study, smeared cracks are assumed to form in radial direction as tangential stresses exceed the tensile strength of concrete $f_{c t, T}$. For the cracked inner part, softening behaviour of concrete in tension is considered in the current model, as shown in Fig. 4a [5, 10, 14]. Previous research [15] indicated that when concrete is exposed to high temperature its overall behaviour becomes more ductile. Since the damage of the concrete at elevated temperatures is more diffused, the characteristic length of the concrete $\left(l_{c h}\right)$ is increased. This is due to the increasing fracture energy $\left(G_{F}\right)$ and the decreasing tensile strength $\left(f_{c t}\right)\left(l_{c h}=G_{F} \frac{E_{c}}{f_{c t}^{2}}\right)[15]$. This phenomenon is considered in the current model. Hence, smeared strain of concrete at elevated temperatures $\varepsilon_{u, T}$ increases when temperature increases, as shown in Fig. $4 \mathrm{~b}$.

Therefore, the tensile stress of concrete $\sigma_{t, T}$ can be determined as:

$$
\begin{aligned}
\sigma_{t, T}=E_{0, T} \varepsilon_{t, T} & \left(\varepsilon_{t, T} \leq \varepsilon_{c t, T}\right) \\
\sigma_{t, T}=f_{c t, T}\left[1-\frac{0.85\left(\varepsilon_{t, T}-\varepsilon_{c t, T}\right)}{\varepsilon_{1, T}-\varepsilon_{c t, T}}\right] & \left(\varepsilon_{c t, T}<\varepsilon_{t, T} \leq \varepsilon_{1, T}\right) \\
\sigma_{t, T}=0.15 f_{c t, T} \frac{\varepsilon_{u, T}-\varepsilon_{t, T}}{\varepsilon_{u, T}-\varepsilon_{1, T}} & \left(\varepsilon_{1, T}<\varepsilon_{t, T} \leq \varepsilon_{u, T}\right)
\end{aligned}
$$


where $\varepsilon_{u, T}$ is the smeared strain of concrete at elevated temperatures when tensile stress equal to zero, and $\varepsilon_{u, T}=\beta \varepsilon_{c t, T}$. In the previous researches, in order to determinate the softening branch of stress-strain curve in tension, different values of $\beta$ were used. In the most cases, the selection of the factor $\beta$ was based on the type of the problem analysed and experience of the researchers. The value of $\beta$ used was in the range of 10-25 [16]. For assessing the influence of the value of $\beta$ used on the current model, the sensitivity analyses by using three different values ( $\beta=10, \beta=15, \beta=25$ ) at temperatures of $300{ }^{\circ} \mathrm{C}$ and $500{ }^{0} \mathrm{C}$ were conducted. The results are shown in Fig. 5. It is evident that the value of $\beta$ used has a considerable influence on the bond stress and slip curve. For simplicity it is reasonable to use $\beta=15$ as an average value in this study. Also $\varepsilon_{1, T}=\frac{2}{9} \varepsilon_{u, T}$ is used [16].

$\varepsilon_{t, T}$ is the average tangential strain at a radial distance $r$, which can be expressed in terms of tangential elongation, $\delta_{t}$ as:

$$
\varepsilon_{t, T}=\frac{\delta_{t}}{2 \pi r}
$$

When the tensile stress $\sigma_{t, T}$ reaches to the tensile strength of concrete $f_{c t, T}$, just before the cracks form at a radial distance $r=R_{i}$ (see Figs. 2 and 3), by neglecting the effect of Poisson's ratio, the total elongation can be expressed as [5]:

$$
\delta_{t}=2 \pi r \varepsilon_{t, T} \approx 2 \pi R_{i} \varepsilon_{c t, T}
$$

Substitute Eq. (9) into Eq. (8), one can be obtained as

$$
\varepsilon_{t, T}=\frac{R_{i}}{r} \varepsilon_{c t, T}
$$

At , $r=R_{s}$

$$
\varepsilon_{t, 0}=\frac{R_{i}}{R_{s}} \varepsilon_{c t, T}
$$

where $\varepsilon_{t, 0}$ is the smeared tangential strain of concrete at the rebar interface; $\varepsilon_{c t, T}=f_{c t, T} / E_{0, T}$, and $E_{0, T}$ is the initial elasticity modulus of concrete at elevated temperatures. 
Now, the total radial stress at the interface between concrete and steel bar $P_{T}^{i}$ equals to the contribution of the uncracked outer part to the radial stress $P_{0, T}^{i}$ plus the contribution from the cracked inner part in which the softening behaviour of concrete is taken into account. Hence, $P_{T}^{i}$ can be calculated as:

$$
P_{T}^{i}=P_{0, T}^{i}+\frac{1}{R_{s}} \int_{R_{s}}^{R_{i}} \sigma_{t, T}(r) d r
$$

The integration in Eq. (12) can be solved by using Eqs. (5)-(7) as [5]:

$$
\begin{aligned}
I= & \int_{R_{s}}^{R_{i}} \sigma_{t, T}(r) d r=\frac{f_{c t, T}}{\varepsilon_{1, T}-\varepsilon_{c t, T}}\left[\left(\varepsilon_{1, T}-0.15 \varepsilon_{c t, T}\right)\left(R_{i}-R_{s}\right)-0.85 R_{i} \varepsilon_{c t, T} \ln \left(\frac{R_{i}}{R_{s}}\right)\right] \quad\left(\varepsilon_{c t, T}<\varepsilon_{t, T} \leq \varepsilon_{1, T}\right) \\
I= & \int_{R_{s}}^{R_{i}} \sigma_{t, T}(r) d r=\left[\frac{0.15 f_{c t, T}}{\varepsilon_{u, T}-\varepsilon_{1, T}}\left(\varepsilon_{u, T} \frac{R_{i} \varepsilon_{c t, T}-R_{s} \varepsilon_{1, T}}{\varepsilon_{1, T}}-R_{i} \varepsilon_{c t, T} \ln \left(\frac{R_{i} \varepsilon_{c t, T}}{R_{s} \varepsilon_{1, T}}\right)\right)\right]+ \\
& {\left[\frac{f_{c t, T}}{\varepsilon_{1, T}-\varepsilon_{c t, T}}\left(\left(\varepsilon_{1, T}-0.15 \varepsilon_{c t, T}\right) \frac{R_{i}\left(\varepsilon_{1, T}-\varepsilon_{c t, T}\right)}{\varepsilon_{1, T}}-0.85 R_{i} \varepsilon_{c t, T} \ln \left(\frac{\varepsilon_{1, T}}{\varepsilon_{c t, T}}\right)\right)\right] \quad\left(\varepsilon_{1, T}<\varepsilon_{t, T} \leq \varepsilon_{u, T}\right) }
\end{aligned}
$$

\section{Entirely cracked stage:}

At this stage, concrete cover is completely cracked, the confining action of concrete is diminished and the splitting failure is occurred. However, for simplicity, this stage is not considered in this paper.

After the calculation of $P_{T}^{i}$ from Eq. (12), the bond stress $\tau_{T}^{i}$ can be determined as $[2,4,6]$ :

$$
\tau_{T}^{i}=P_{T}^{i} \cot (\alpha)
$$

where $\alpha$ is the effective face angle (see Fig. 1) which equal to $30^{\circ}$ to $45^{\circ}[4,7]$. It is assumed $\alpha=42^{0}$ in the current model if $\alpha$ is not given in the test.

In the current model, the effect of high temperature on the bond characteristics is considered by taking into account the degradation of concrete properties at elevated temperatures. The concrete properties at ambient temperature specified in Eurocode 2 EN 1992-1-1 [17] are used. The elastic modulus of concrete at elevated temperatures $E_{0, T}$ is calculated based on Eurocode 2 EN 1992-1-2 [18]. However, the degradation of the concrete tensile strength at elevated temperatures $f_{c t, T}$ specified in Eurocode 2 EN 1992-1-2 is not used in this paper. This is mainly due to in Reference [18] $f_{c t, T}=0$ when the concrete temperature is higher than 
$600{ }^{\circ} \mathrm{C}$. Hence, the degradation of the tensile strength for concrete at elevated temperatures proposed by Aslani and Bastami [19] is adopted in this study. That is:

$$
f_{c t, T}=f_{c t}\left[\begin{array}{lc}
1.02-0.00098 \times T & 20<T \leq 300{ }^{0} \mathrm{C} \\
0.965-0.0001 \times T-9 \times 10^{-7} T^{2}-3 \times 10^{-9} T^{3}+3.2 \times 10^{-12} T^{4} & 300<T \leq 900{ }^{\circ} C \\
0.0 & T>900{ }^{\circ} C
\end{array}\right]
$$

where $f_{c t}$ is the concrete tensile strength at ambient temperature and $T$ is the concrete temperature.

One of the main contributions of this paper is to develop a procedure for calculating the slippage of the rebar and to establish the relationship between the bond stress and bond slip. In order to determinate the bond-slip relationship, the maximum bond-slip $S_{\max }$ obtained from the bond stress-slip model in CEB- FIP Model Code 90 [10] and the maximum bond stress $\tau_{\max }$ obtained from the partially cracked thick wall cylinder theory described above are used. Hence, the bond-slip of the rebar can be determined by considering the maximum slip $S_{\max }$ at the maximum bond stress point $\tau_{\max }$. In the current model it is assumed that $S_{\max }$ equals to $0.6 \mathrm{~mm}$ for splitting failure at concrete cover $C=d_{b}$, and $1.0 \mathrm{~mm}$ for pull-out failure at concrete cover $C \geq 5 d_{b}$ in good bond conditions [10], where $d_{b}$ is rebar diameter. By taking linear interpolation for $1 \geq C / d_{b} \geq 5, S_{\max }$ can be determined for different values of concrete cover and rebar's diameters as:

$$
S_{\max }=0.6+0.1 \times\left(\frac{C}{d_{b}}-1\right)
$$

As shown in Fig. 6 (b) $\tau_{\max }$ can be found when the slop of the bond stress- $R_{i}$ curve equals to zero, that is

$$
\frac{d \tau_{T}^{i}}{d R_{i}}=\frac{\tau_{T}^{i+1}-\tau_{T}^{i}}{R_{i+1}-R_{i}}=0.0
$$

As shown in Fig. 6, the bond stress-slip curve and bond stress $-R_{i}$ curve are defined as two parts. For the first part of the curves, where $0 \leq S_{i} \leq S_{s}$ and $0 \leq R_{i} \leq R_{s}$ : 
$\tau_{s}$ is the bond stress at $R_{i}=R_{s}$ and $\tau_{s}=\tau_{T}^{i=1}$ (see Eq. (15)). The slip $S_{s}$ at $\tau_{s}$ can be calculated as:

$$
S_{s}=\tau_{\max }\left(\frac{\tau_{s}}{S_{\max }}\right)^{1 / \beta}
$$

where $\beta=0.4$ is used.

Then, the bond stress at elevated temperatures $\tau_{T}$ can be calculated:

$$
\tau_{T}=\tau_{\max }\left(\frac{S}{S_{\max }}\right)^{\beta}
$$

For the second part of bond stress-slip curve, where $S_{i}>S_{s}$ and $R_{i}>R_{s}$ :

The relationship between $R_{i}$ and $S_{i}$ can be taken as a liner relationship (see Fig. 7) [20]. The slop $m$ of the line in Fig. 7 can be calculated as:

$$
m=\frac{\Delta R_{i}}{\Delta S_{i}}=\frac{R_{\max }-R_{s}}{S_{\max }-S_{s}}
$$

Then, the slip for the second part $S_{i}$ is:

$$
S_{i}=\frac{R_{i}-R_{s}}{m}+S_{s}
$$

where $i=1,2,3 \ldots n$, and $n$ is the total number of steps. When $R_{i}=R_{c}$ then $\tau_{\text {fail }}=\tau_{T}^{n}$.

The calculation procedure proposed in this model for determining the bond stress-slip curve at each temperature step can be summarised as the following:

(1) To calculate the bond-stress $\tau_{T}^{i}$ and bond-slip $S_{i}$ for the second part of bond stressslip curve $\left(S_{s}<S_{i} \leq S_{\text {fail }}\right.$ and $R_{s} \leq R_{i} \leq R_{c}$ ) (see Fig. 6):

$$
\begin{aligned}
& \Delta R=\frac{R_{c}-R_{s}}{n} \\
& i=1,2,3, \ldots \mathrm{n}: \\
& \quad R_{i}=R_{i-1}+\Delta R \\
& \quad \text { calculate } P_{0, T}^{i} \text { (Eq. (4)) }
\end{aligned}
$$


calculate $P_{T}^{i}$ (Eq. (12))

calculate $\tau_{T}^{i}$ (Eq. (15))

Calculate $\tau_{\max }$ and $R_{\max }$ (Eq. (18))

Calculate $S_{s}$ (Eq. (19))

$i=1,2,3, \ldots \mathrm{n}$ :

calculate $S_{i}$ (Eq. (22))

(2) To calculate the bond-stress $\tau_{T}^{i}$ and bond-slip $S_{i}$ for the first part of bond stress-slip curve $\left(\mathrm{O}<S_{i} \leq S_{s}\right.$ and $\left.0 \leq R_{i} \leq R_{s}\right)$ (see Fig. 6):

$$
\begin{aligned}
& \Delta S=\frac{S_{s}}{n} \\
& i=1,2,3, \ldots \mathrm{n}: \\
& \quad S_{i}=S_{i-1}+\Delta S \\
& \quad \text { calculate } \tau_{T}^{i} \text { (Eq. (20)) }
\end{aligned}
$$

\section{Incorporated bond stress-slip model into Vulcan software}

In order to demonstrate the robustness and accuracy of the model proposed above, the developed bond stress-slip model has been incorporated into the VULCAN software [12] for simulating the bond characteristics between concrete and reinforcing steel bar at elevated temperatures. Huang [9] has developed a two-node bond-link element within the VULCAN to consider the bond characteristics between concrete and steel bars under fire conditions. As shown in Fig. 8, the bond link element has two nodes with zero length. Each node of the element has three translational degrees of freedom $u, v, w$ and three rotational degrees of freedom $\theta_{x}, \theta_{y}, \theta_{z}$, where $x, y, z$ are the local coordinates of the steel bar in which $x$ is the direction of longitudinal axis of the reinforcing steel bar element. It is assumed that the slip between reinforcing steel and concrete is related only to the longitudinal axis direction ( $x$ direction) (see Fig. 8(a)). Hence, the bonding force $F_{T, x}$ between the concrete and reinforcing steel bar for the bond element is obtained as:

$$
F_{T, x}=A \tau_{T}
$$


where $A$ is the contact area between the concrete and the reinforcing steel bar $A=U L$, where $U$ is the perimeter of the steel bar and $L$ is length of the steel bar which contributes to the node connected by the bond element.

Hence in the local co-ordinate, referenced to the reinforcing steel bar element, the nodal force increment vector, $\boldsymbol{\Delta} \mathbf{F}$ of the element can be related to its nodal displacement increment vector $\Delta \mathbf{u}$ as

$$
\left\{\begin{array}{l}
\Delta F_{x, 1} \\
\Delta F_{y, 1} \\
\Delta F_{z, 1} \\
\Delta M_{x, 1} \\
\Delta M_{y, 1} \\
\Delta M_{z, 1} \\
\Delta F_{x, 2} \\
\Delta F_{y, 2} \\
\Delta F_{z, 2} \\
\Delta M_{x, 2} \\
\Delta M_{y, 2} \\
\Delta M_{z, 2}
\end{array}\right\}=\left[\begin{array}{cccccccccccc}
k_{1} & 0 & 0 & 0 & 0 & 0 & -k_{1} & 0 & 0 & 0 & 0 & 0 \\
0 & k_{2} & 0 & 0 & 0 & 0 & 0 & -k_{2} & 0 & 0 & 0 & 0 \\
0 & 0 & k_{3} & 0 & 0 & 0 & 0 & 0 & -k_{3} & 0 & 0 & 0 \\
0 & 0 & 0 & k_{4} & 0 & 0 & 0 & 0 & 0 & -k_{4} & 0 & 0 \\
0 & 0 & 0 & 0 & k_{5} & 0 & 0 & 0 & 0 & 0 & -k_{5} & 0 \\
0 & 0 & 0 & 0 & 0 & k_{6} & 0 & 0 & 0 & 0 & 0 & -k_{6} \\
-k_{1} & 0 & 0 & 0 & 0 & 0 & k_{1} & 0 & 0 & 0 & 0 & 0 \\
0 & -k_{2} & 0 & 0 & 0 & 0 & 0 & k_{2} & 0 & 0 & 0 & 0 \\
0 & 0 & -k_{3} & 0 & 0 & 0 & 0 & 0 & k_{3} & 0 & 0 & 0 \\
0 & 0 & 0 & -k_{4} & 0 & 0 & 0 & 0 & 0 & k_{4} & 0 & 0 \\
0 & 0 & 0 & 0 & -k_{5} & 0 & 0 & 0 & 0 & 0 & k_{5} & 0 \\
0 & 0 & 0 & 0 & 0 & -k_{6} & 0 & 0 & 0 & 0 & 0 & k_{6}
\end{array}\right]\left\{\begin{array}{l}
\Delta u_{1} \\
\Delta v_{1} \\
\Delta w_{1} \\
\Delta \theta_{x, 1} \\
\Delta \theta_{y, 1} \\
\Delta \theta_{z, 1} \\
\Delta u_{2} \\
\Delta v_{2} \\
\Delta w_{2} \\
\Delta \theta_{x, 2} \\
\Delta \theta_{y, 2} \\
\Delta \theta_{z, 2}
\end{array}\right\}
$$

For reinforcing steel bars, apart from the relative slip along the longitudinal axis direction ( $x$ direction) between concrete and steel bars the concrete prevents relative movement of reinforcing steel bars in other directions. It is therefore reasonable to assume that common nodes of the concrete and reinforcing bar elements have identical rotations and movements in $y$ and $z$ directions. Hence, in this model $k_{2}, k_{3}, k_{4}, k_{5}, k_{6}$ in Eq. (24) are assumed to have infinite magnitude $\left(=10^{15}\right)$.

Coefficient $k_{1}$ is the tangent stiffness coefficients of the bond-link element related to the axis of the reinforcing steel bar element. At each temperature step $j$, for each iteration $i k_{1}^{j, i}$ can be determined from the load-slip relationship as:

$$
k_{1}^{j, i}=\frac{d F_{T, x}^{j, i}}{d S_{x}^{j, i}}=A \frac{d \tau_{T}^{j, i}}{d S_{x}^{j, i}}
$$

For the first part of bond stress-slip curve, where $0 \leq S_{j} \leq S_{s}, k_{1}^{j, i}$ can be calculated as: 


$$
k_{1}^{j, i}=A \frac{\tau_{\max }^{j}}{S_{\max }^{j}}\left(\frac{S_{x}^{j, i}}{S_{\max }^{j}}\right)^{\beta-1}
$$

For the second part of bond stress-slip curve, where $S_{j}>S_{s}$, a numerical differentiation method is used to calculate coefficient $k_{1}^{j}$.

$$
k_{1}^{j, i}=A \frac{\tau_{i+1}^{j}-\tau_{i-1}^{j}}{S_{i+1}^{j}-S_{i-1}^{j}}
$$

Using incremental analysis, the increment of bond force $\Delta F_{T, x}^{j, i}$ can be related to the increment of slip, $\Delta S_{x}^{j, i}$ by the tangent stiffness relationship, that is:

$$
\Delta F_{T, x}^{j, i}=k_{1}^{j, i} \Delta S_{x}^{j, i}
$$

in which

$$
\Delta S_{x}^{j, i}=\Delta u_{2}^{j, i}-\Delta u_{1}^{j, i}
$$

where $\Delta u_{1}^{j, i}$ and $\Delta u_{2}^{j, i}$ are the increments of displacement in the direction of $\Delta F_{T, x}^{j}$ at the nodes 1 and 2 of the bond-link element, respectively.

As shown in Fig. 8, in the current model a reinforced concrete beam is represented as an assembly of plain concrete beam, reinforcing steel bar and bond-link elements. Both plain concrete beam and reinforcing steel bar elements are modelled using the 3-node beam element developed by the second author [12], in which the thermal expansions of concrete and steel are considered. Hence their effect, related to the direction of longitudinal axis of the reinforcing steel bar, on the bond-link element developed in this paper is taken into account. However, the thermal expansions of both concrete and steel in the radius direction of the steel bar have not been considered in the current model for simplicity. This is because that the strain compatibility at the interface between steel bar and surrounding concrete is not always maintained when the pull-out load is applied [21], especially when the pull-out load reaches to the capacity of the bond. Also the reduction in the steel bar's diameter due to the Poisson effect during the pull-out load could compensate the influence of the differential thermal expansion between the steel bar and concrete.

As mentioned above the plain concrete beam is modelled using the 3-node beam element [12]. The cross-section of the beam element is sub-divided into segments to consider the temperature variation within the cross-section. Hence, in principal the temperature variation 
within the concrete rings around the bars (see Figs. 2 and 3) can be considered in the current model. However, in the following validation section it is assumed that the temperatures of the concrete rings around the bars are uniform and equal to the temperature of steel bar for simplicity. This is a reasonable assumption for all pull-out tests [21].

\section{Validations}

The proposed model presented above was validated using a series of previous experimental results at both ambient and elevated temperatures. This section consists of two parts: the first part is to compare the predicted bond stress-slip curves with previous experimental pull-out test results; the second part of the validation is to validate the bond link element with the new developed bond stress-slip model for modelling the bond characteristics of reinforced concrete structural members.

\subsection{Validations of the bond stress-slip model}

\subsubsection{Bond stress-slip curve at ambient temperature}

Table 1 gives information for the experimental tests carried by Xiao and Falkner [22], John Robert Prince and Bhupinder [23], and Lee and Noguchi [24]. In the Table $1, l_{b}$ is the embedded length of the rebar inside the specimens and $d_{b}$ is the diameter of the rebar. All tested material properties and geometric details of the specimens were used as the input data for the modelling. Figs. 9(a) to (f) show the comparison of predicted and measured bond stress-slip curves for the tests. It is clear that the predictions of the current model agreed reasonable well with the experimental results. This confirms that the proposed model can be used for predicting bond stress-slip curve between concrete and reinforcing steel bars at ambient temperature.

\subsubsection{Bond stress-slip curve at elevated temperatures}

The details of pull-out tests at elevated temperatures used in this validation are summarised in Table 2. As mentioned above, the tested data on the bond characteristics between the concrete and steel bars at elevated temperatures are limited. Hence, the proposed model was validated using the available experimental results of pull-out testes at elevated temperatures. All the material properties and geometries of the specimens in the tests were used as the input data for the model's predictions. 
Firstly, the tests conducted by Diederichs and Schneider [1] were used. In this study deformed steel bar of $16 \mathrm{~mm}$ was used and the specimens were made with a bond length of $80 \mathrm{~mm}$ and a concrete cover of $78 \mathrm{~mm}$. The test temperatures were in the range of $20^{\circ} \mathrm{C}$ to $800^{\circ} \mathrm{C}$ with a heating rate of $1^{\circ} \mathrm{C} / \mathrm{min}$. Fig. 10 (a) illustrates the comparison of predicted and measured bond stress-slip curves for different temperatures. It can be seen from the figure that good correlation between the model predictions and tested results was achieved. It is clear that the strength of the bond was degraded significantly at high temperatures.

Secondly, the tests carried out by Morley and Royles [25] were modelled. In these tests, the test temperatures were in the range of $20^{\circ} \mathrm{C}-750^{\circ} \mathrm{C}$ with the heating rate of $2^{\circ} \mathrm{C} / \mathrm{min}$. The lengths of these samples were $300 \mathrm{~mm}$ with a rebar embedded length of $32 \mathrm{~mm}$. The details of the tests are given in Table 2. Figs. 10(b) and (c) show the comparison between the tested results and the current model predictions for the concrete covers of $55 \mathrm{~mm}$ and $46 \mathrm{~mm}$, respectively. It is evident that the current model's predictions are in reasonable agreement with the tested data.

Thirdly, the tests conducted by Haddad and Shannis [26] were used for the validations. In these tests, special cylindrical moulds of $82 \mathrm{~mm}$ diameter with a circular opening of $20 \mathrm{~mm}$ at the bases were used to cast pull out specimens. The steel bar used was $18 \mathrm{~mm}$ in diameter with imbedded length of $150 \mathrm{~mm}$. The temperatures used in the tests were $23^{\circ} \mathrm{C}, 600^{\circ} \mathrm{C}$ and $800^{\circ} \mathrm{C}$ with heating rate of $20^{\circ} \mathrm{C} / \mathrm{min}$. The test details are given in Table 2 . The comparison between the current model's predictions and tested results is shown in Fig. 10(d). Again reasonable agreement between the tested data and the model's predictions is achieved.

Finally, the tests done by Haddad et al. [27] were adopted to further validate the current model. In these tests, the specimens were in cuboid shape with dimensions of (100x100x400mm). The steel bar of $20 \mathrm{~mm}$ with embedded length of $150 \mathrm{~mm}$ was used in this study. The range of the test temperatures was $23^{\circ} \mathrm{C}$ to $700^{\circ} \mathrm{C}$. Fig. 10 (e) presents the comparison of the current model's predictions with tested results. It can be seen that the bond strength predicted by current model is significant higher than tested results at ambient temperature. However, there is very little differences if compared the tested results between $23{ }^{0} \mathrm{C}$ and $350{ }^{0} \mathrm{C}$. This is contradicted with the tested results generated by other two researchers presented above. Therefore, the test errors may be the reasons to explain the strange behaviours. 


\subsection{Validations of the bond-link element with new developed bond stress-slip model}

As mentioned in Section 3, the developed bond stress-slip model has been incorporated into the VULCAN software [12] for simulating the bond characteristics between concrete and reinforcing steel bar at elevated temperatures. Hence, in this section three different types of tests were used to validate the new bond-link element. The details are as the following:

\subsubsection{Modelling pull-out test at ambient temperature}

Viwathanatepa et al [8] conducted several pull-out tests at the University of California in 1979. One specimen was used for the validation. The test specimen was an anchored \#8 (25 $\mathrm{mm})$ diameter reinforced bar in a well confined block of 25 in $(635 \mathrm{~mm})$ anchorage length. The specimen was subjected to a monotonic pull-out load under displacement control at one end only. The tested material properties of concrete and steel are as follows: the concrete cylinder compressive strength is $f_{c k}=32.4 \mathrm{MPa}$; yield strength of the reinforcing steel is $f_{y}=468.4 \mathrm{MPa}$. These material properties were used as an input data for the modelling. The finite element mesh for modelling this test involved 4 three-node plain concrete elements, 4 three-node reinforcing steel bar elements. The nodes of the concrete elements were connected to the nodes of the steel bar elements by the two-node bond-link elements. Hence, total of 9 two-node bond-link elements were used in this case.

In this validation the predicted steel stresses are compared with the tested data and analytical study results generated by Viwathanatepa et al [8]. Figs. 11(a) to (c) show the stress distribution along the anchored length of the reinforcing steel bar at three different load levels. It is clear from the figures that the results generated by the current model agree reasonable well with the tested results. To demonstrate the robustness of the current model, Fig. 12 shows the predicted bond stress field along the anchored length for different loaded end slips. Also Fig. 13 presents the predicted end slips versus total pull out load for the test. These results indicate that the strength of the bond between concrete and reinforcing steel plays a very important role to influence the load capacity of reinforced concrete structural members.

\subsubsection{Modelling simply supported RC beam at ambient temperature}

In order to examine the capability of the developed model a simply supported RC beam J4 tested by Burns and Siess [28] is used for the validation. Fig. 14 illustrates the details of J4 beam. The tested concrete strength is $f_{c k}=33.34 \mathrm{MPa}$ and the reinforcing steel bars are $2 \mathrm{x}(\# 8)$ 
steel bars with yield strength of $f_{y}=309.6 \mathrm{MPa}$ and elastic modulus of $E_{s}=203404 \mathrm{MPa}$. Those tested material properties were used as the input data for the modelling. Due to the symmetry of the beam, only half of the beam was modelled in this study. For modelling the beam J4, 4 three-node plain concrete elements, 8 three-node reinforcing steel bar elements with 198.2 $\mathrm{mm}$ off-set below the central reference axis and $63.5 \mathrm{~mm}$ right and left referenced to the central reference axis, and 18 bond-link elements were employed. Fig. 15 shows the comparison of predicted and measured mid-span deflections of J4 beam with different bond conditions. In the figure, for the case of perfect bond it was assumed that there was no slip between steel reinforcing bar and surrounding concrete; for the case of bond-slip the interaction between reinforcing steel bar and concrete was considered by using bond-link element developed here. It is evident that the bond-slip of the reinforcing steel bars has a negligible effect on the load-deflection response at room temperature.

\subsubsection{Modelling fire tests of RC beams}

Lin et al. [29] curried out a series of tests on the reinforced concrete beams under fire conditions. Two types of heating curve were adopted in these tests; the ASTM fire curve and the Short Duration High Intensity (SDHI). In this validation, four beams were modelled. Beam-1 and Beam-3 were heated using ASTM Fire and Beam-5 and Beam- 6 were subjected to the SDHI fire. The details of the beams 1, 3, 5 and 6 used for modelling are shown in Fig. 16. The tested concrete's compressive strengths of beams $1,3,5$ and 6 are $f_{c k}=27.68 \mathrm{MPa}$, $f_{c k}=31.5 \mathrm{MPa}, f_{c k}=33.37 \mathrm{MPa}$ and $f_{c k}=34.54 \mathrm{MPa}$, respectively. The tested steel yield strengths are $f_{y}=487.27 \mathrm{MPa}$ for the bar \#7 (22.2 mm in diameter) and $f_{y}=509.54 \mathrm{MPa}$ for \#8 $(25.4 \mathrm{~mm}$ in diameter). Degradation of the concrete compressive strength and the steel bars yield strength at elevated temperatures specified in EN 1992-1-2 [18] was adopted for concrete and steel bar elements.

In order to mode the tested beams, the first step was to perform the thermal analysis. As shown in Fig. 16 the arrangement of reinforcing steel bars in the tested beams varied along the length of the beam. In this study for the thermal analysis the cross-sections of the beams were divided into 448 segments ( 28 rows x 16 columns). The steel bars were represented as steel segments within the cross-section and varied along the length of the beam. Thermal analysis was conducted to predict temperature histories within the beam cross-sections. As shown in Fig. 16, there are four layers of main reinforcing steel within the cross-sections. In presenting the results of the thermal analysis, the reinforcing steel layers are denoted in 
sequence from bottom to top as Layers 1 to 4 . The predicted temperature histories of the main reinforcing steel layers for Beams 1 and 5, which were subsequently used for structural analysis, are shown in Figs 17 and 18, together with those test results which are available. It is evident that reasonable agreement has been achieved between test and prediction.

Predicted temperature history from the thermal analysis for each concrete and steel segment was used as the temperature input data for the structural analysis. Hence, in the structural analysis the same segmentation of the cross sections used in the thermal analysis was adopted for the plain concrete elements in which the volumes occupied by the steel bars were represented as void segments. The temperatures of the reinforcing steel bars were represented by the temperatures of the steel segments at related locations within the cross-section considered. In this study, a total of 10 three-node plain concrete elements with 448 segments, 48 three-node reinforcing steel bar elements with off-set from the central reference axis of the beam and 104 bond-link elements were employed for modelling the whole beam. As shown in Fig. 16, the load $P$ was kept constant at $44.48 \mathrm{kN}$ during each fire test, although the cantilever force $P_{0}$ varied as the test progressed. The measured values of $P_{0}$ for the beams and the test values of material properties at room temperature were used for the modelling.

Due to the beam was continued over the right-hand support as shown in Fig. 16, the maximum vertical deflection of the beam was formed around the position $2600 \mathrm{~mm}$ from the left-hand support. The comparison of predicted and measured maximum deflections of Beam 1 and Beam 3 under ASTM fire condition are shown in Figs. 19 and 20, respectively. Again, these two beams were modelled using perfect bond and bond-slip conditions. For the perfect bond condition, it was assumed that there was no slip between steel reinforcing bar and surrounding concrete. For the bond-slip condition, the interaction between reinforcing steel bar and concrete was considered by using current bond-link element. Under ASTM fire condition it is evident from the figures that before $120 \mathrm{~min}$ test time the behaviours of the beams with two bond conditions are almost identical. This is due to the average temperature at bond between concrete and reinforcing steel bar is less than $400^{\circ} \mathrm{C}$ (see Fig. 17). Hence, the strength of the bond does not decrease significant. However, the influence of the bond became significant when the test time beyond $180 \mathrm{~min}$ in which the average temperature at the bond was above $500^{\circ} \mathrm{C}$ (see Fig. 17).

Figs. 21 and 22 illustrate the comparison between the predicted and tested maximum deflections of Beam 5 and Beam 6 under SDHI Fire condition. It can be seen that the influence of the bond conditions is not significant. This is due to that the maximum 
temperature of the bond is less than $400^{\circ} \mathrm{C}$ (see Fig. 19). From the validations, it is evident that the new bond-link element with the developed bond stress-slip model is capable to consider the influence of bond characteristics between concrete and reinforcing steel bars on the structural behaviours of reinforced concrete structural members under fire conditions. This study indicates that for fire resistance design of reinforced concrete structures the normal perfect bond assumption is un-conservative.

\section{Conclusions}

In this paper a numerical model has been developed to simulate the bond-slip characteristic between the concrete and reinforcing steel bar at elevated temperatures. The model is based on the thick-wall cylinder theory with the considering of the partially cracked of concrete cover, and the smeared crack of concrete in tension. Hence, the model takes into account the splitting failure of concrete cover. The degradation of the bond strength at elevated temperatures is related to the concrete material properties changed with temperature. The developed bond stress-slip model has been incorporated into two-node bond-link element within the VULCAN software for analysing the impacts of bond characteristic on structural behaviours of reinforced concrete structural members in fire. A series of validations have been conducted using the previous tested data generated by different researchers. Reasonable good agreements have been achieved between the model's predictions and tested results. Based on this study, the following conclusions can be drawn:

- The model presented in this paper is able to predict the bond-slip characteristic between the concrete and reinforcing steel bar at elevated temperatures. The model takes into account the variation of the concrete properties, concrete covers and steel bars' geometries.

- The study indicates that the strength of the bond between the concrete and reinforcing steel bars plays a very important role to affect the fire resistance of the reinforced concrete structures, especially when the temperature of the reinforcing steel bar is high (more than $500^{\circ} \mathrm{C}$ ). Therefore, the assumption of the perfect bond condition for the analysis of reinforced concrete structures under fire conditions is un-conservative.

- For fire engineering design the failure of bond between concrete and reinforcing steel, particularly in beams with little or no continuity, may be the key criterion for fire resistance, but this clearly needs further parametric studies before general rules can be proposed. 


\section{Acknowledgments}

The first author gratefully acknowledges the financial support of the Ministry of Higher Education and Scientific Research of Iraqi Government for this Ph.D. project.

\section{References}

[1] Diederichs U. and Schneider U. Bond strength at high temperatures. Magazine of concrete research $1981 ; 33(115): 75-84$.

[2] Pothisiri T. and Panedpojaman P. Modelling of mechanical bond-slip for steel-reinforced concrete under thermal loads. Engineering Structures 2013; 48:497-507.

[3] Huanzi W. An analytical study of bond strength associated with splitting of concrete cover. Engineering Structures 2009; 31:968-975.

[4] Tepfers R. Cracking of concrete cover along anchored deformed reinforcing bars. Magazine of Concrete Research 1979; 31(106):3-12.

[5] Wang X. and Liu X. A strain-softening model for steel-concrete bond. Cement and Concrete Research 2003; 33:1669-1673.

[6] Bigaj A. J. Structural dependence of rotation capacity of plastic hinges in RC beams and slabs. PhD Thesis, Technische University Delft; 1999.

[7] Nielsen C. V. and Bicanic N. Radial fictitious cracking of thick-walled cylinder due to bar pull-out. Magazine of Concrete Research 2002; 54(3):215-221.

[8] Viwathanatepa, S., Popov, E.P. and Bertero, V.V. Effects of generalized loadings on bond of reinforcing bars embedded in confined concrete blocks. Report No EERC 7922, Earthquake Engineering Research Center, University of California, Berkeley; 1979.

[9] Huang Z. Modelling the bond between concrete and reinforcing steel in fire. Engineering Structures 2010; 32:3660-3669.

[10] CEB-FIP Model code 1990, final draft, committe euro-international du beton, Bulletin d'information No.203-205; 1991.

[11] Bazant ZP, Kaplan MF. Concrete at high temperatures. Longman Group Limited, 1996.

[12] Huang Z., Burgess IW, Plank RJ. Three-dimensional analysis of reinforced concrete beam-column structures in fire. J Struct Eng, ASCE 2009; 135(10):1201-12. 
[13] Timoshenko S. and Goodier J. N., Theory of elasticity. McGraw-Hill Book Company; 1951.

[14] Pantazopoulou S. J. and Papoulia K. D. Modeling cover-cracking due to reinforcement corrosion in RC structures. Journal of Engineering Mechanics, ASCE 2001; 127(4):342 - 351.

[15] Fire Design of Concrete Structures-Structural Behaviour and Assessment. fib Fédération internationale du béton - Building, Fireproof, fib Bulletin 46, 2008.

[16] Barzegar-Jamshidi F. and Schnobrich W.C. Nonlinear Finite Element Analysis of Reinforced Concrete Under Short Term Monatomic Loading. A report on a research project, University of Illinois at Urbana-Champaign, research series No.530, 1986.

[17] Eurocode 2 EN 1992-1-1: Design of concrete structures - Part 1-1: General rules and rules for buildings. London: British Standards Institution; 2004.

[18] EN 1992-1-2. Eurocode 2, design of concrete structures- part 1-2: general rules structural fire design. London: British Standards Institution; 2004.

[19] Aslani F. and Bastami M. Constitutive relationships for normal-and high-strength concrete at elevated temperatures. ACI Material Journal 2011; 108(4):355-364.

[20] Sakai T., Kanakubo T., Yonemaru K. and Fukuyama H. Bond splitting behavior of contiuous fiber reinforced concrete members. Fiber Reinforced Polymer for Reinforced Concrete Structures, ACI SP-188 1999; 1131-1144.

[21] Pothisiri T. and Panedpojaman P. Modeling of bonding between steel rebar and concrete at elevated temperatures. Construction and Building Materials 2012; 27:130140.

[22] Xiao J. and Falkner H. Bond behaviour between recycled aggregate concrete and steel rebars. Construction and Building Materials 2007; 21:395-40.

[23] John Robert Prince M. and Bhupinder S. Bond behaviour of deformed steel bars embedded in recycled aggregate concrete. Construction and Building Materials 2013; $49: 852-862$.

[24] Lee H. and Noguchi T. Evaluation of the bond properties between concrete and reinforcement as a function of the degree of reinforcement corrosion. Cement and Concrete Research 2002; 32:1313-1318.

[25] Morley P.D. and Royles R. Response of the bond in reinforced concrete to high temperatures, Magazine of Concrete Research 1983; 35(123):67-74. 
[26] Haddad R.H. and Shannis L. G. Post-fire behavior of bond between high strength pozzolanic concrete and reinforcing steel. Construction and Building Materials 2004; $18: 425-435$.

[27] Haddad R.H., Al-Saleh R.J. and Al-Akhras N.M., Effect of elevated temperature on bond between steel reinforcement and fiber reinforced concrete, Fire Safety Journal $2008 ; 43: 334-343$.

[28] Burns N.H. and Siess C. P. Load-deformation characteristics of beam-column connections in reinforced concrete. Civil engineering Studies SRS No.234, University of Illinois, Urbana; 1962.

[29] Lin TD., Ellingwood B. and Piet O. Flexural and shear behaviour of reinforced concrete beams during fire tests. Report no. NBS-GCR-87-536. Center for Fire Research, National Bureau of Standards; 1987. 


\section{List of Tables and Figures}

Table 1 Details of pull-out test in previous experiments at ambient temperature

Table 2 Details of pull-out tests in previous experiments at elevated temperatures

Fig. 1 Mechanical action between the steel bar and concrete

Fig. 2 Partly cracked concrete cylinder

Fig. 3 Uncracked elastic stage

Fig. 4: (a) Stress-strain curve of concrete in tension (b) Concrete tensile stress-strain curves at different temperatures

Fig. 5 Influence of $\beta$ on the current model at different temperatures

Fig. 6 Proposed curves: (a) Bond stress-slip curve (b) Bond stress - $R_{i}$ curve

Fig. 7 The relationship between the slip and $R_{i}$

Fig. 8 Bond-link element: (a) 2D Coordinates (b) 3D Coordinates

Fig. 9 Comparison of predicted and measured bond stress-slip curves at ambient temperature

Fig. 10 Comparison of predicted and measured bond stress-slip curves at elevated temperatures

Fig. 11 Comparison between the predicted and tested stress distributions along anchored reinforcing steel bar [8]

Fig. 12 Predicted bond stress distributions corresponding to different end-slips for test [8]

Fig. 13 Predicted end-slips vs pull-out force for the test [8]

Fig. 14 Details of J4 beam tested at ambient temperature [28]

Fig. 15 Comparison of predicted and measured mid-span deflections of J4 beam [28]

Fig. 16 Details of tested beams in fire [29]

Fig. 17 Comparison of predicted and measured temperatures of four main reinforcing steel layers for Beam 1 [29]

Fig. 18 Comparison of predicted and measured temperatures of four main reinforcing steel layers for Beam 5 [29]

Fig. 19 Comparison of predicted and measured maximum deflections of Beam1 (ASTM Fire) [29]

Fig. 20 Comparison of predicted and measured maximum deflections of Beam3 (ASTM Fire) [29]

Fig. 21 Comparison of predicted and measured maximum deflections of Beam5 (SDHI Fire) [29]

Fig. 22 Comparison of predicted and measured maximum deflections of Beam6 (SDHI Fire) [29] 


\section{Tables}

Table 1 Details of pull-out test in previous experiments at ambient temperature.

\begin{tabular}{|c|c|c|c|c|c|c|c|}
\hline Reference & specimens & $\begin{array}{c}f_{c k, 20^{\circ} C} \\
(\mathrm{MPa})\end{array}$ & $\begin{array}{c}\text { Bar diameter } \\
d_{b}(\mathrm{~mm})\end{array}$ & $\begin{array}{c}R_{c} \\
(\mathrm{~mm})\end{array}$ & $C / d_{b}$ & $l_{b} / d_{b}$ & $\begin{array}{c}\text { Rib face angle } \\
(\text { degrees })\end{array}$ \\
\hline Xiao and Falkner [20] & RAC-II-0 & 34.0 & 10 & 50 & 4.0 & 5.0 & $55^{\circ}$ \\
John Robert Prince and & A12R0 & 36.9 & 12 & 50 & 3.67 & 5.0 & $45^{\circ}$ \\
Bhupinder [21] & A16R0 & & 16 & 50 & 2.6 & 5.0 & $36^{\circ}$ \\
& A20R0 & & 20 & 50 & 2.0 & 5.0 & $41^{\circ}$ \\
Lee and Noguchi [22] & A25R0 & 24.7 & 13 & 50 & 1.5 & 5.0 & $51^{\circ}$ \\
\hline
\end{tabular}

Table 2 Details of pull-out tests in previous experiments at elevated temperatures.

\begin{tabular}{|c|c|c|c|c|c|}
\hline Reference & $f_{c k, 20^{\circ}(\mathrm{MPa})}$ & $\begin{array}{c}\text { Bar diameter } \\
d_{b}(\mathrm{~mm})\end{array}$ & $R_{c}(\mathrm{~mm})$ & $C / d_{b}$ & $l_{b} / d_{b}$ \\
\hline Diederichs and Schneider [1] & 45.0 & 16 & 86 & 4.88 & 5.0 \\
Morley and Royles [23] & 29.0 & 16 & 63 & 3.44 & 2.0 \\
& & 16 & 54 & 2.88 & 2.0 \\
Haddad and Shannis [24] & 58.8 & 16 & 40 & 2.0 & 2.0 \\
Haddad et al. [25] & 62.3 & 18 & 33 & 1.56 & 2.0 \\
& & 20 & 51 & 1.78 & 8.3 \\
\end{tabular}




\section{Figures}

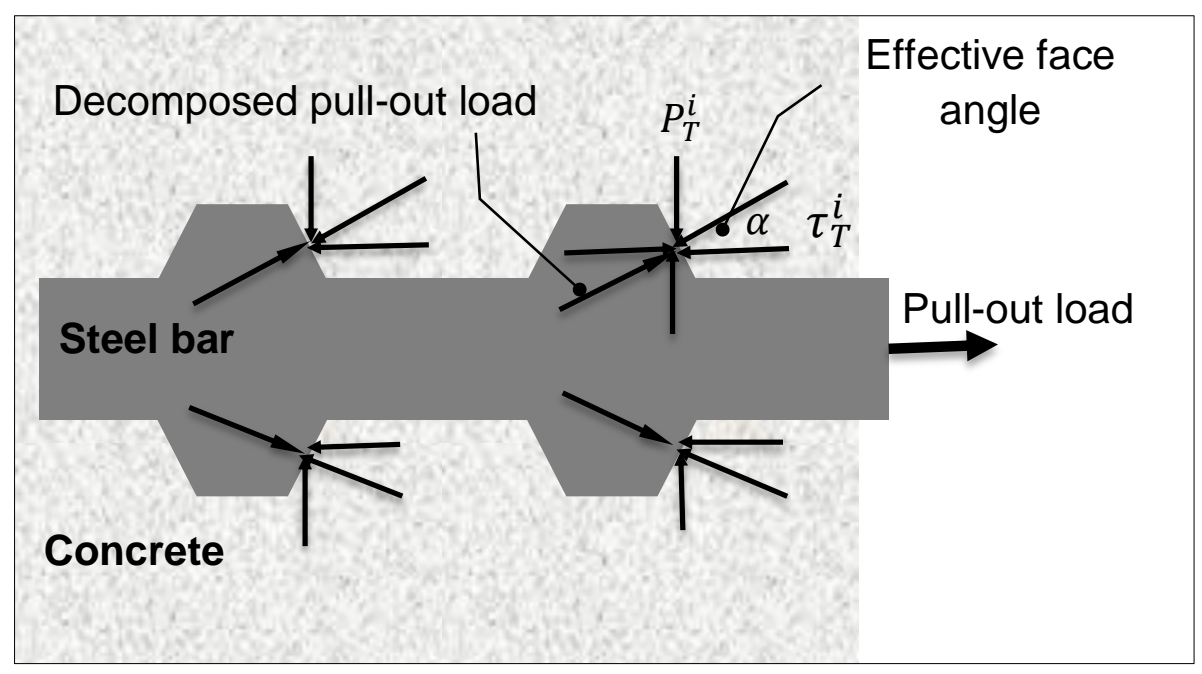

Fig. 1 Mechanical action between the steel bar and concrete

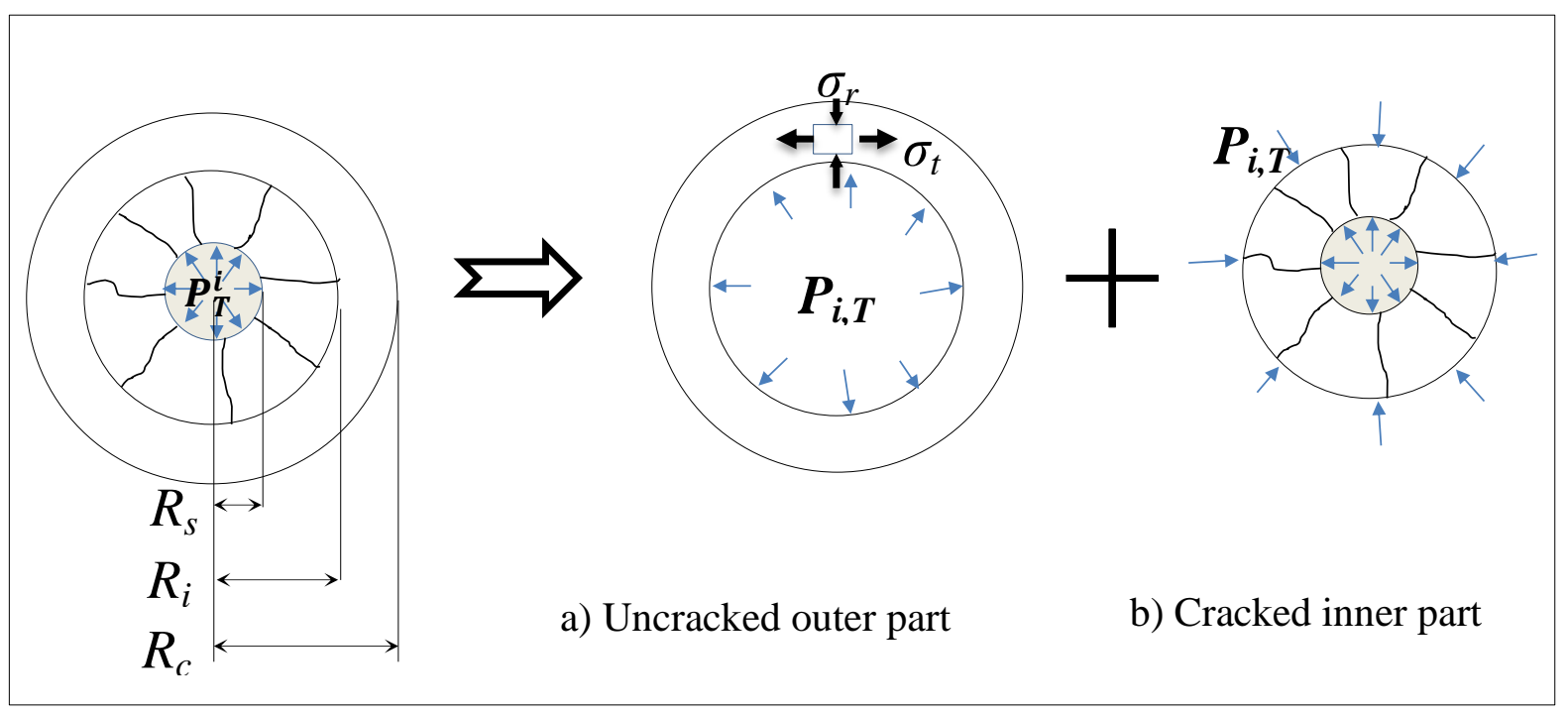

Fig. 2 Partly cracked concrete cylinder 


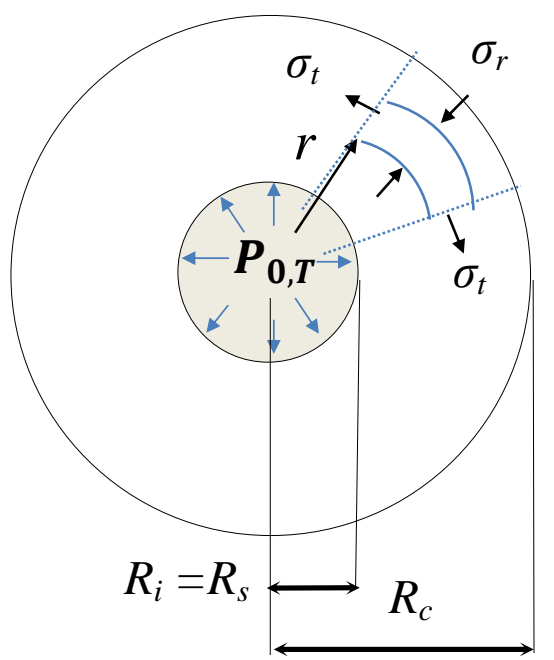

Fig. 3 Uncracked elastic stage 


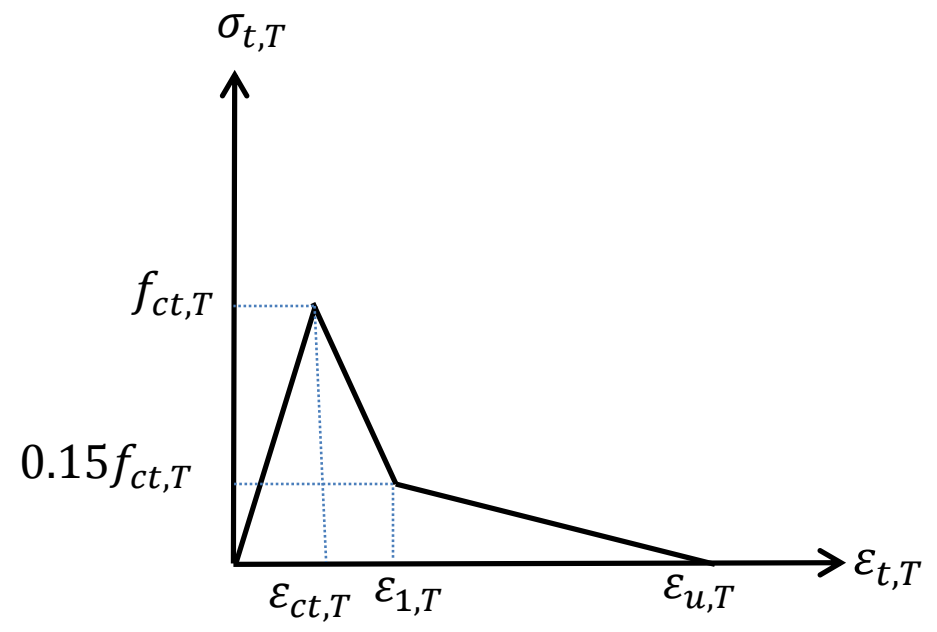

(a)

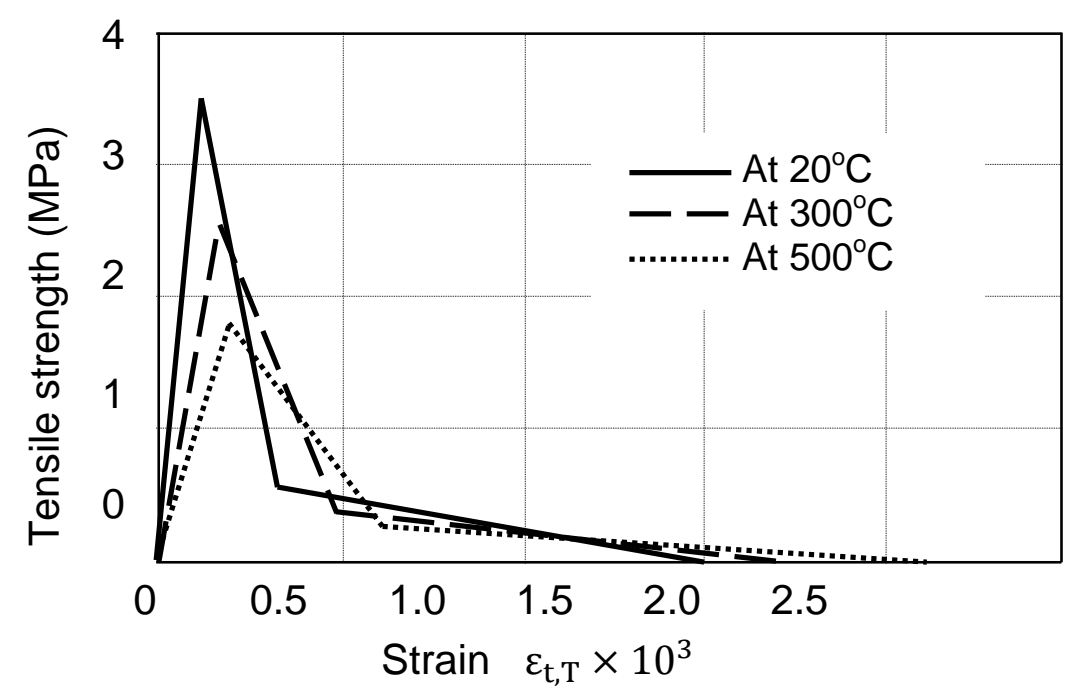

(b)

Fig. 4: (a) Stress-strain curve of concrete in tension (b) Concrete tensile stress-strain curves at different temperatures 


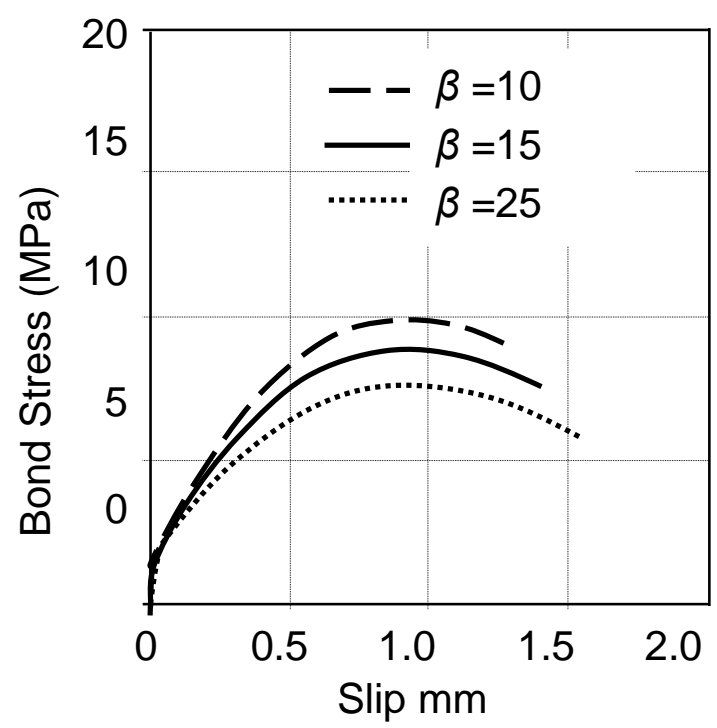

(a)

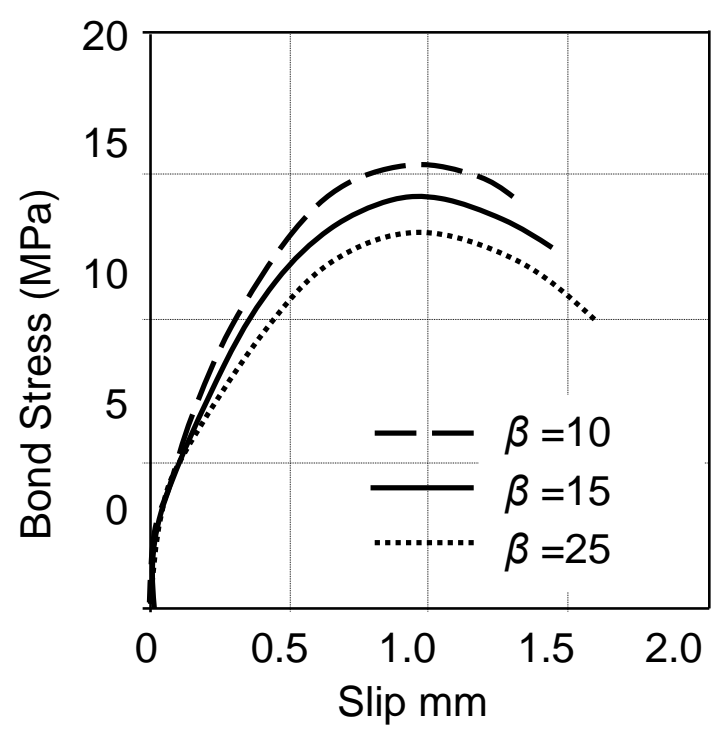

(b)

Fig. 5 Influence of $\beta$ on the current model at different temperatures: (a) At $500^{\circ} \mathrm{C}$ (b) At $300{ }^{\circ} \mathrm{C}$

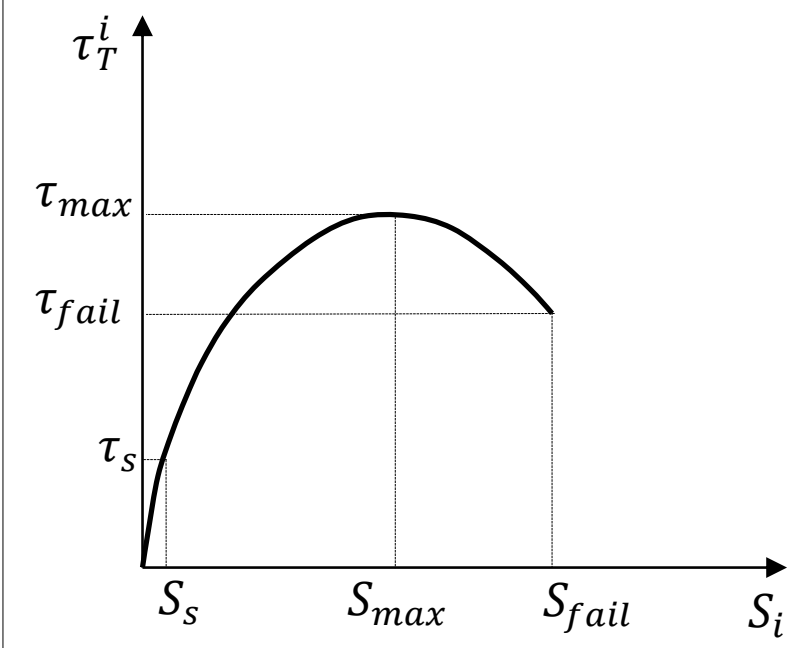

(a)

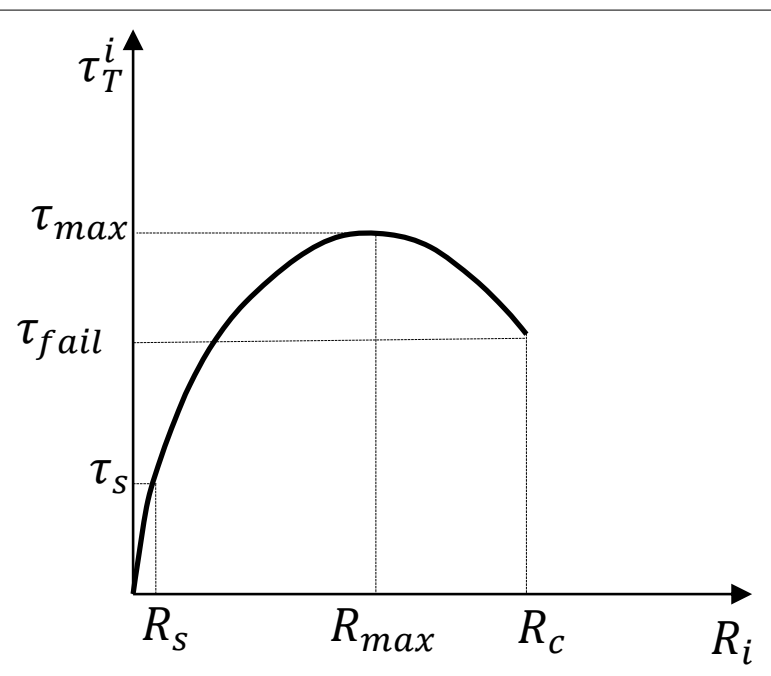

(b)

Fig. 6 Proposed curves: (a) Bond stress-slip curve (b) Bond stress - $R_{i}$ curve 


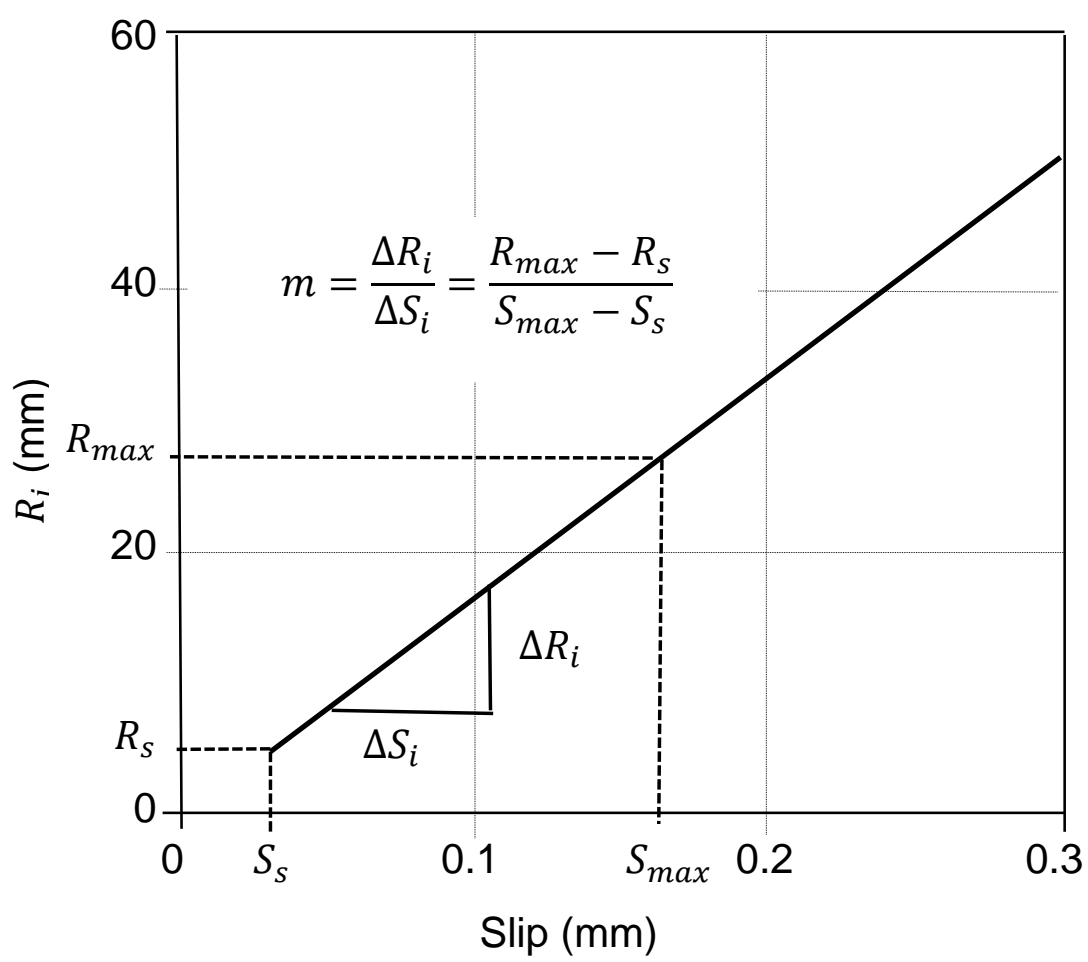

Fig. 7 The relationship between the slip and $R_{i}$ 


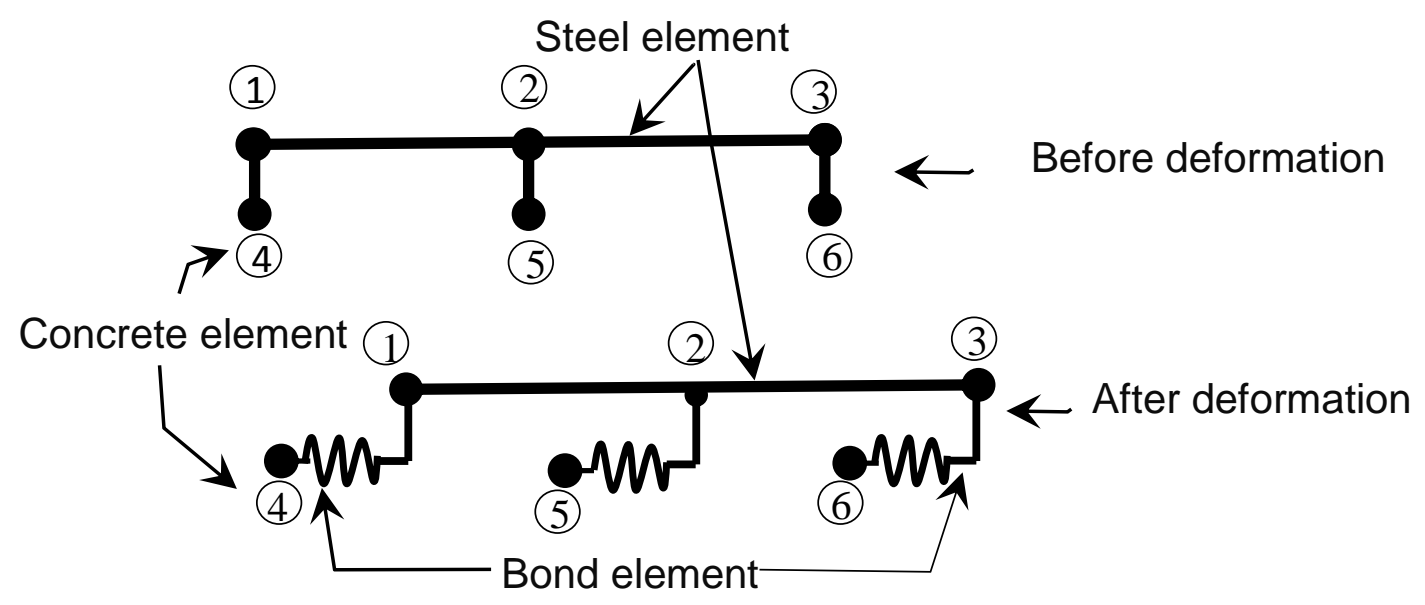

(a)

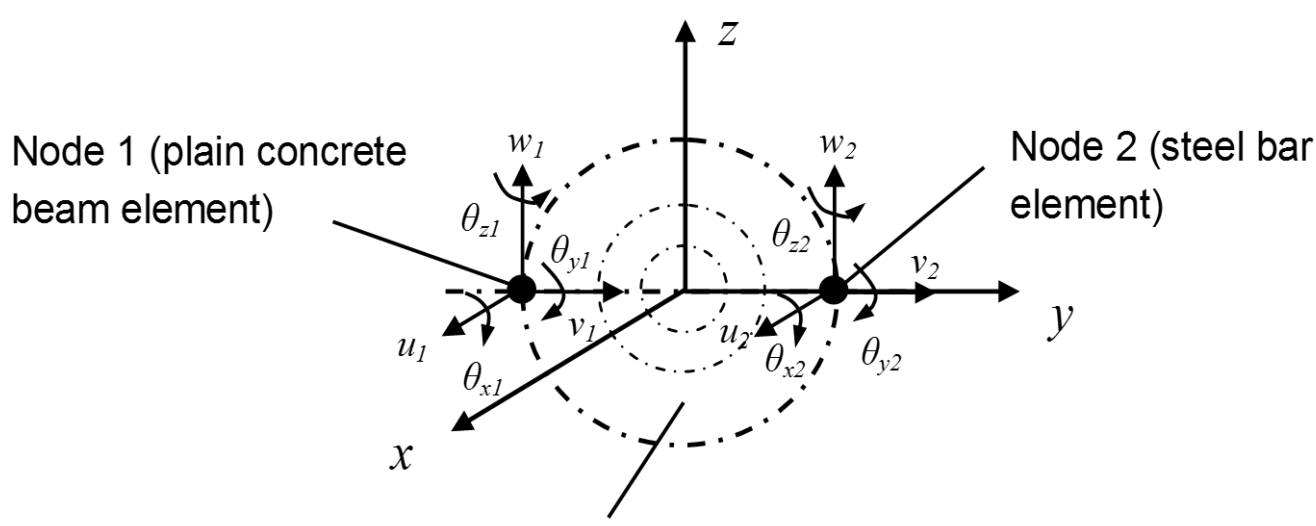

Bond-link element (link node 1 and node2

(b)

Fig. 8 Bond-link element: (a) 2D Coordinates (b) 3D Coordinates 


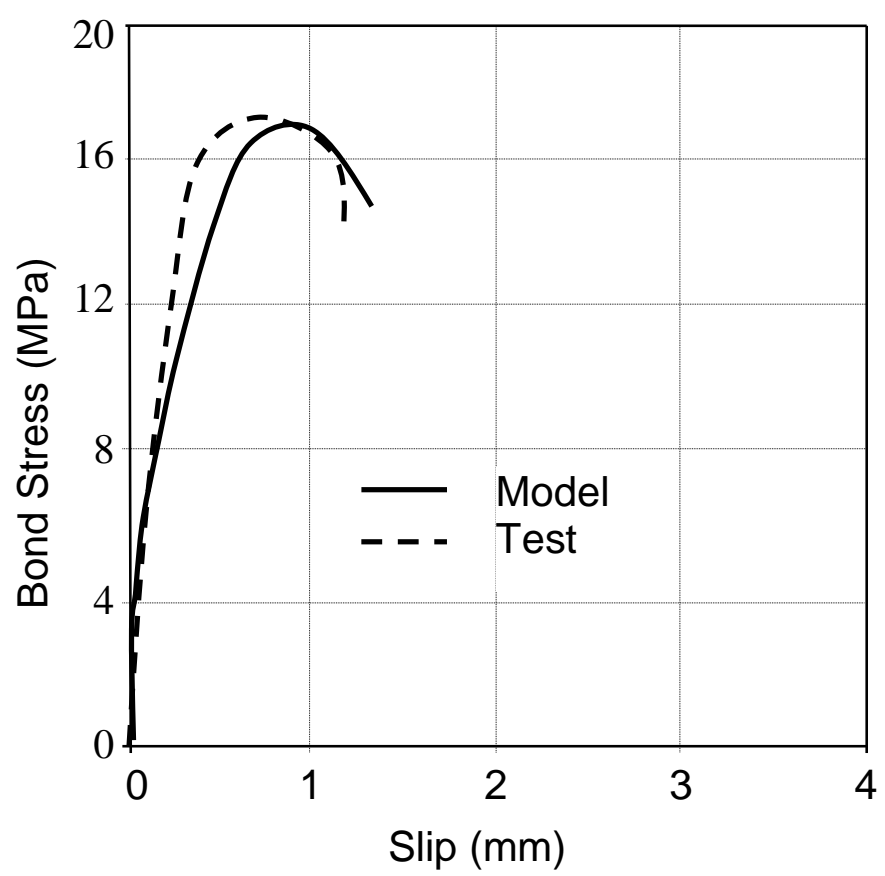

(a) Specimen RAC-II-0 (Xiao and Falkner [22])

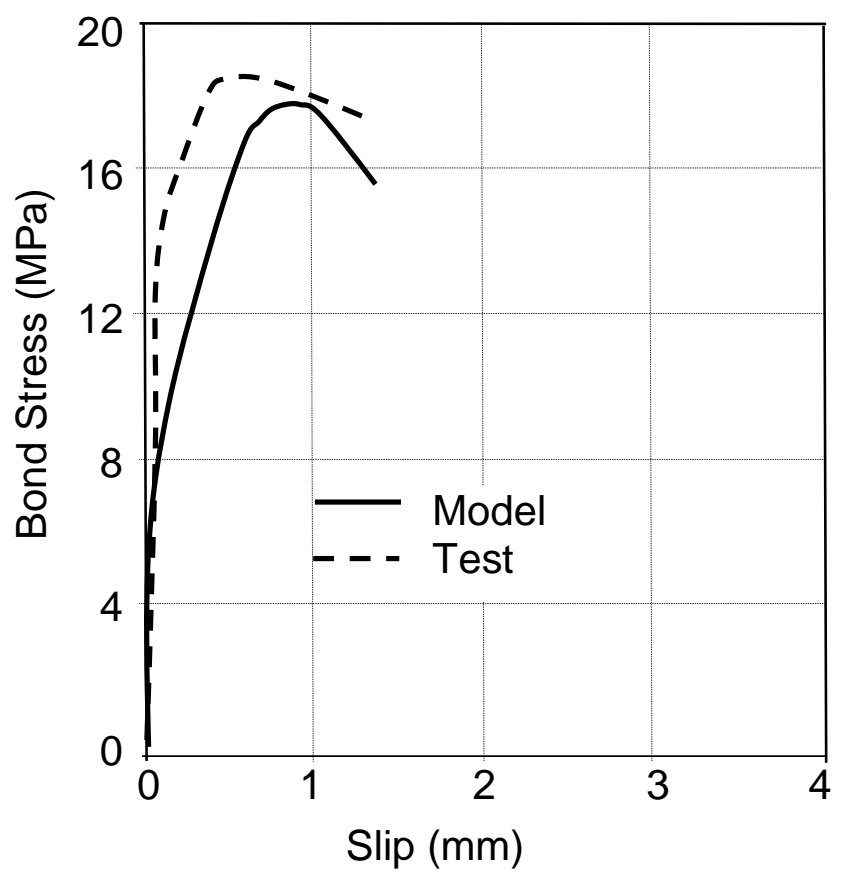

(b) Specimen A12R0 (John Robert Prince and Bhupinder [23]) 


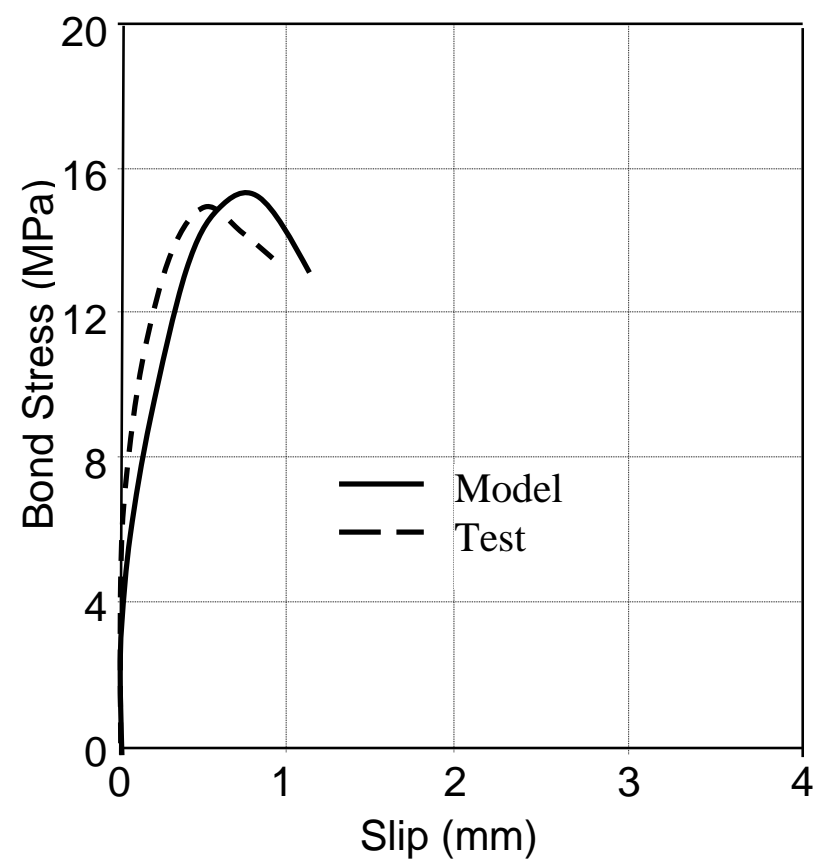

(c) Specimen A16R0 (John Robert Prince and Bhupinder [23])

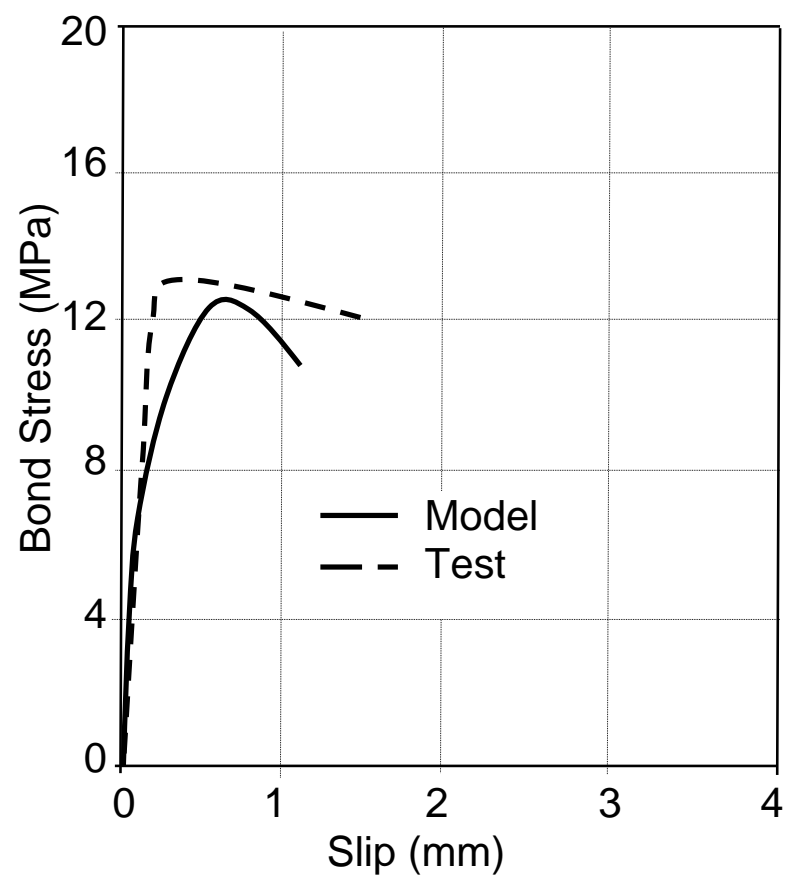

(d) Specimen A20R0 (John Robert Prince and Bhupinder [23]) 


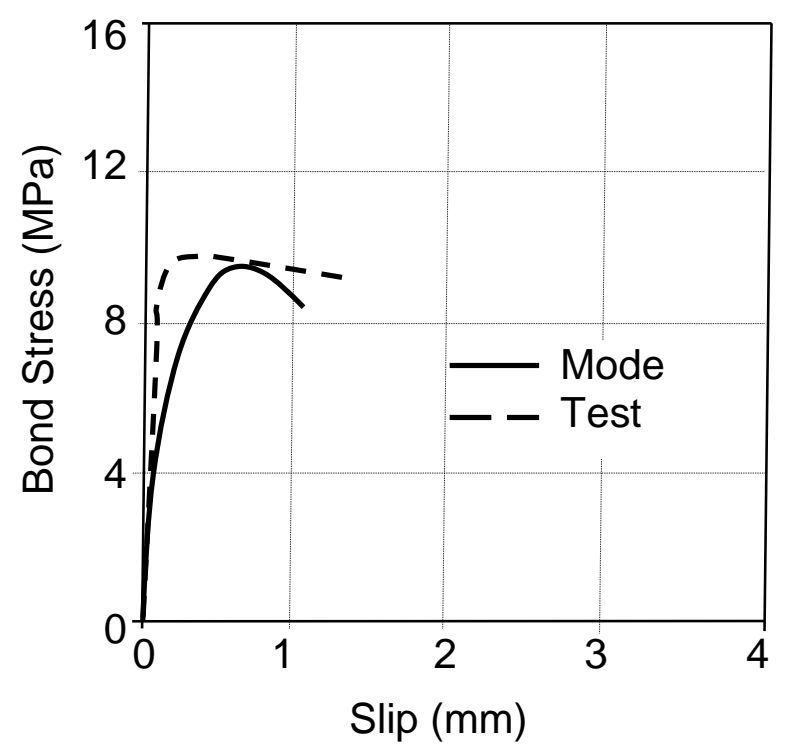

(e) Specimen A25R0 (John Robert Prince and Bhupinder [23])

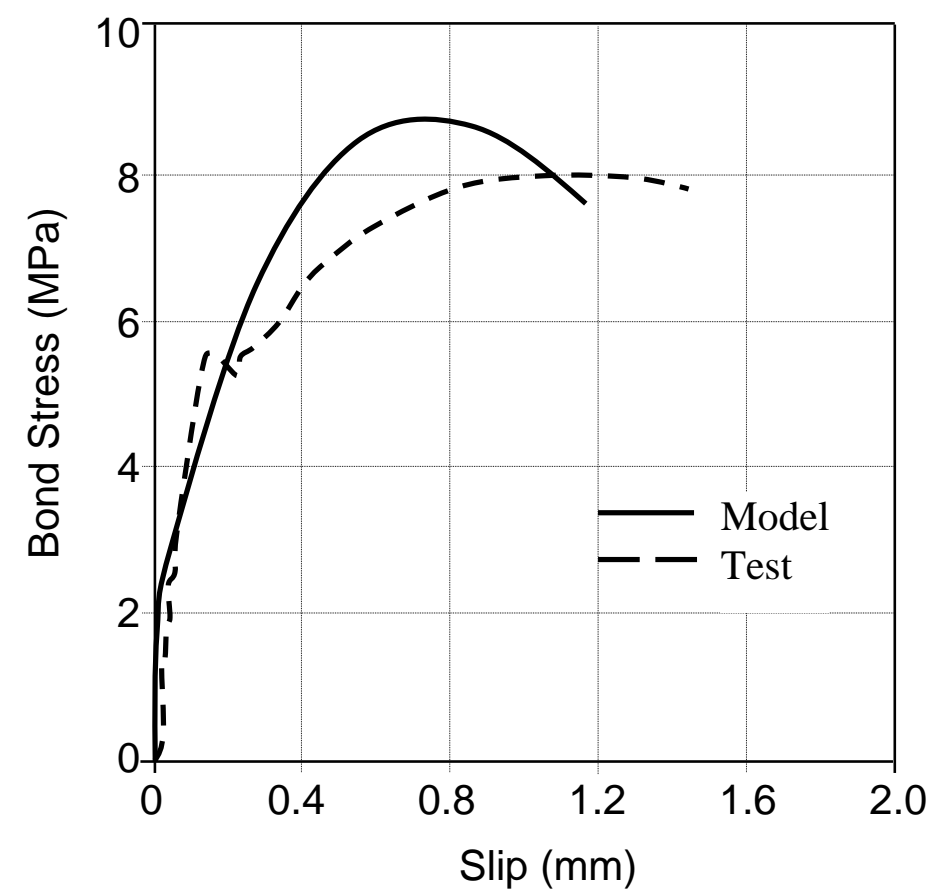

(f) Test conducted by Lee and Noguchi [24]

Fig. 9 Comparison of predicted and measured bond stress-slip curves at ambient temperature 


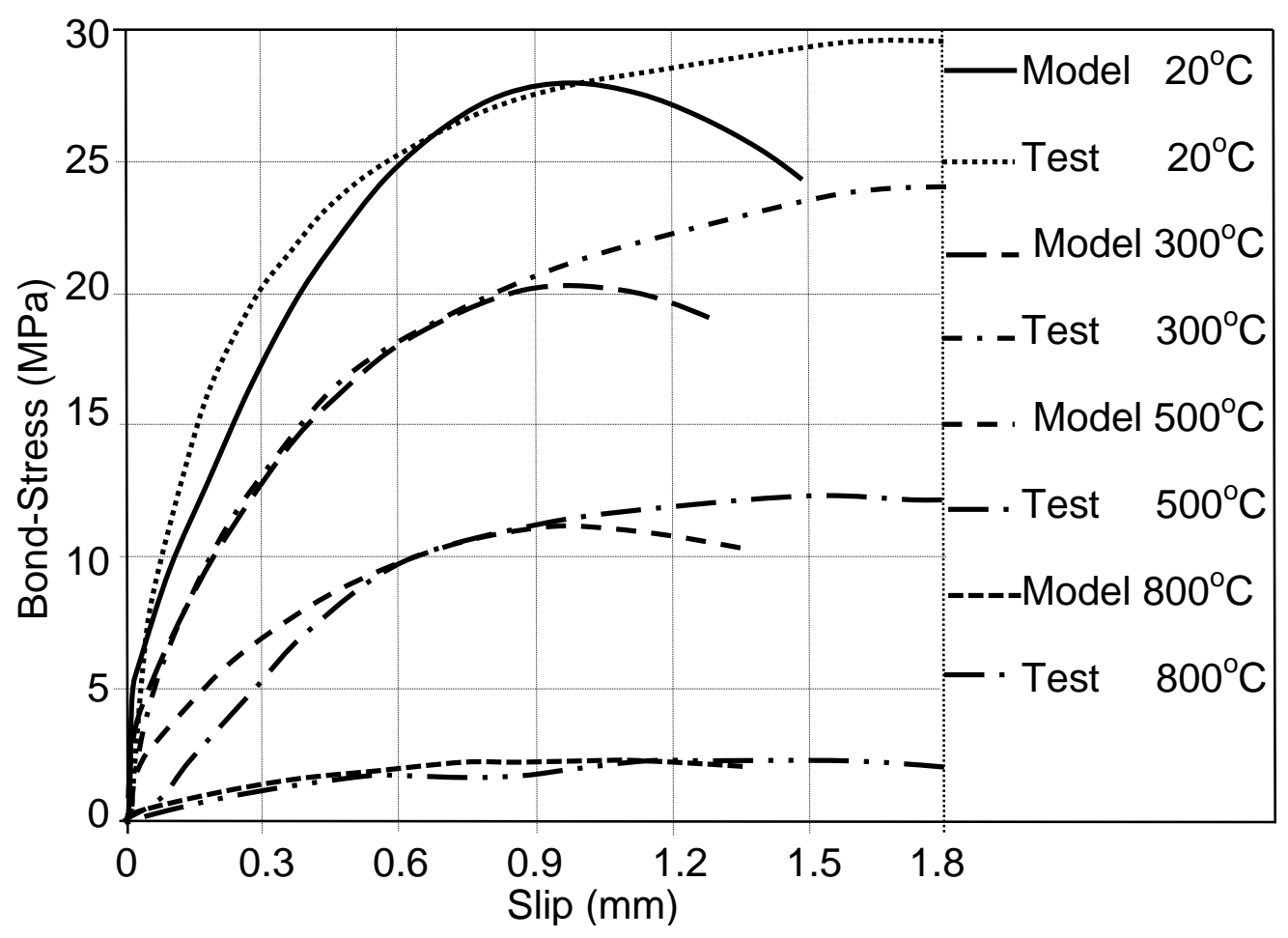

(a) Tested by Diederichs and Schneider [1]

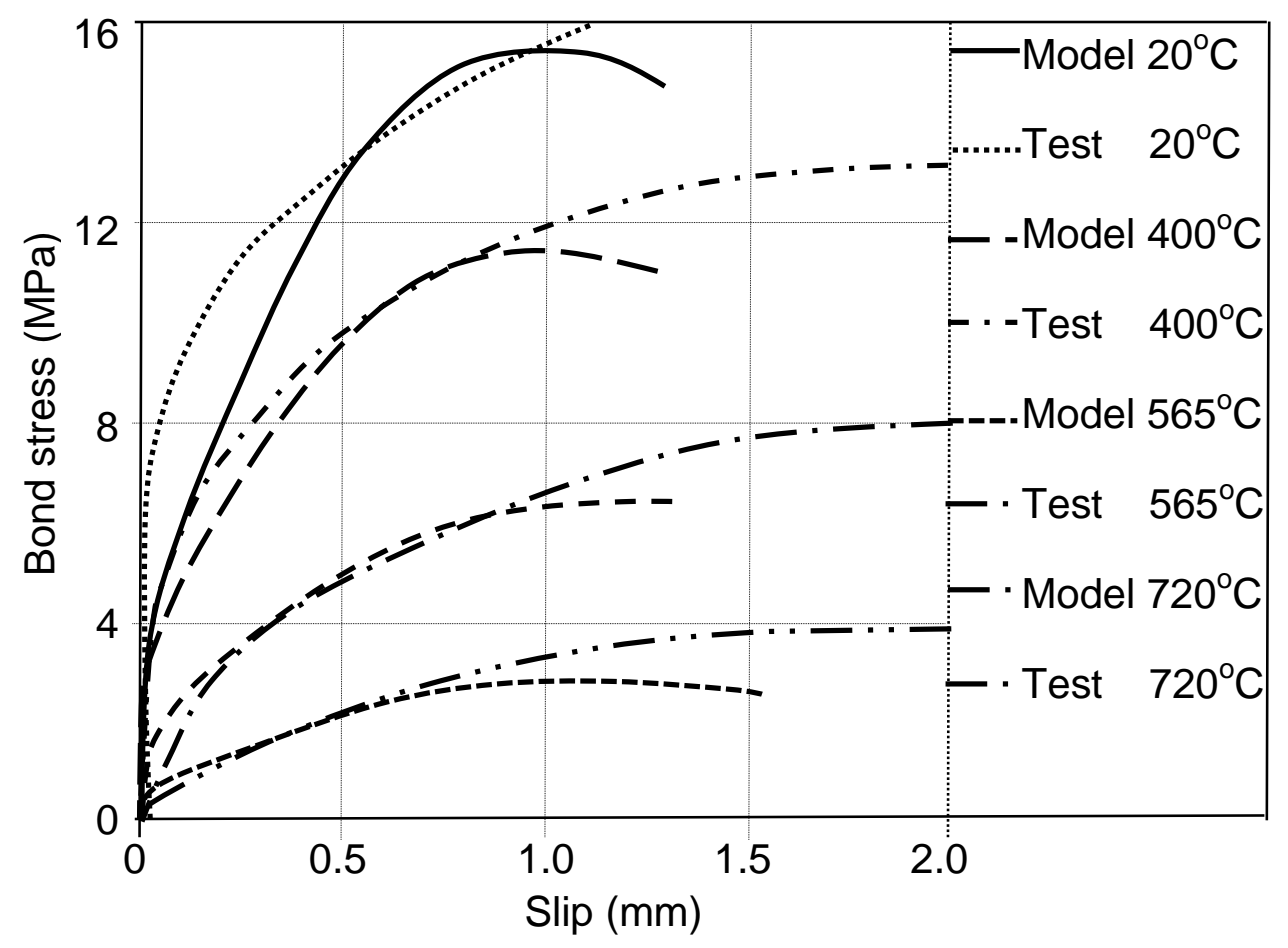

(b) Tested by Morley and Royles [25] $\left(d_{b}=16 \mathrm{~mm}\right.$, concrete cover $\left.55 \mathrm{~mm}\right)$ 


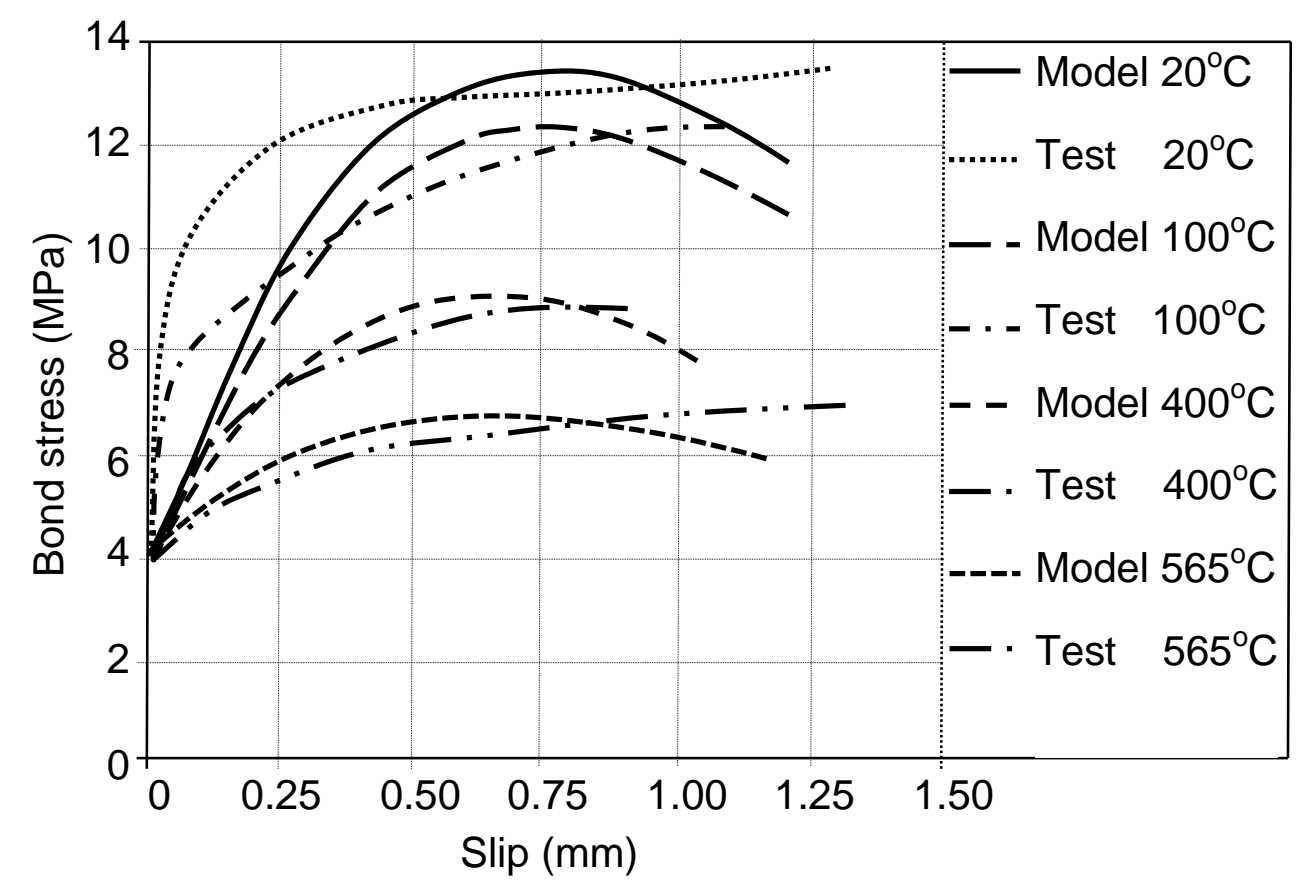

(c) Tested by Morley and Royles [25] $\left(d_{b}=16 \mathrm{~mm}\right.$, concrete cover $\left.46 \mathrm{~mm}\right)$

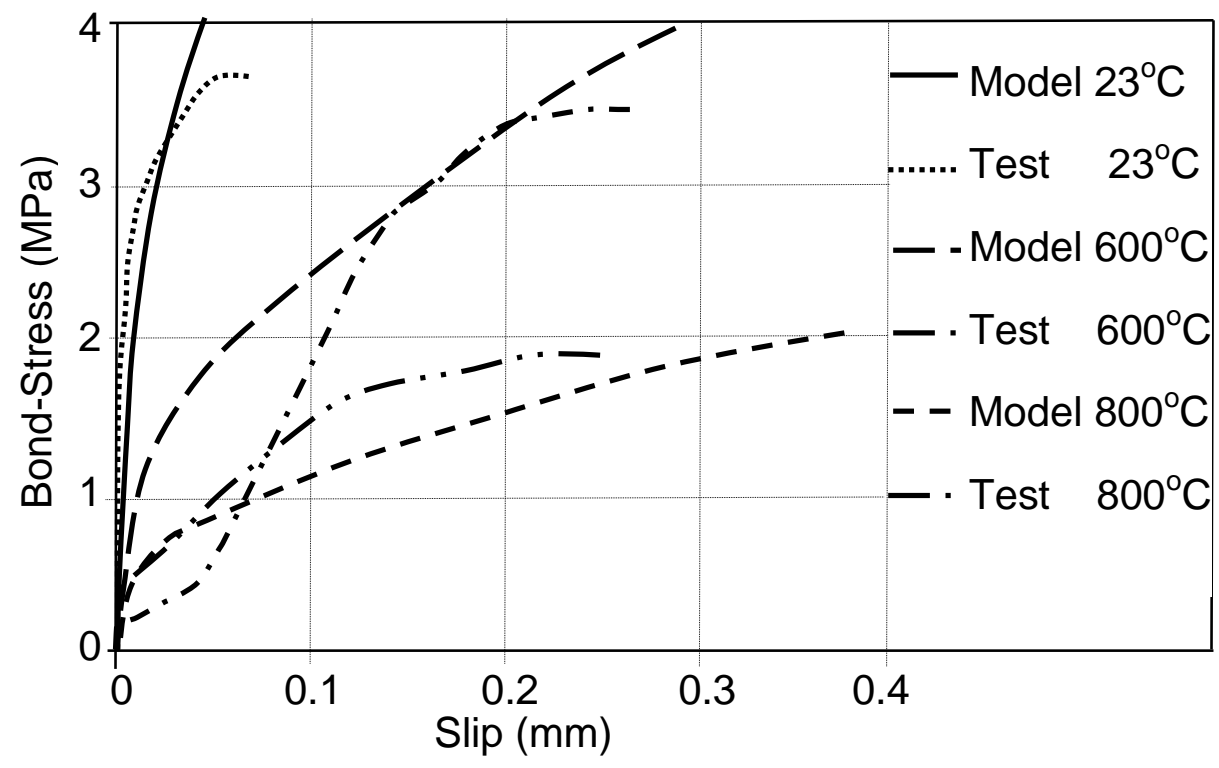

(d) Tested by Haddad and Shannis [26] 


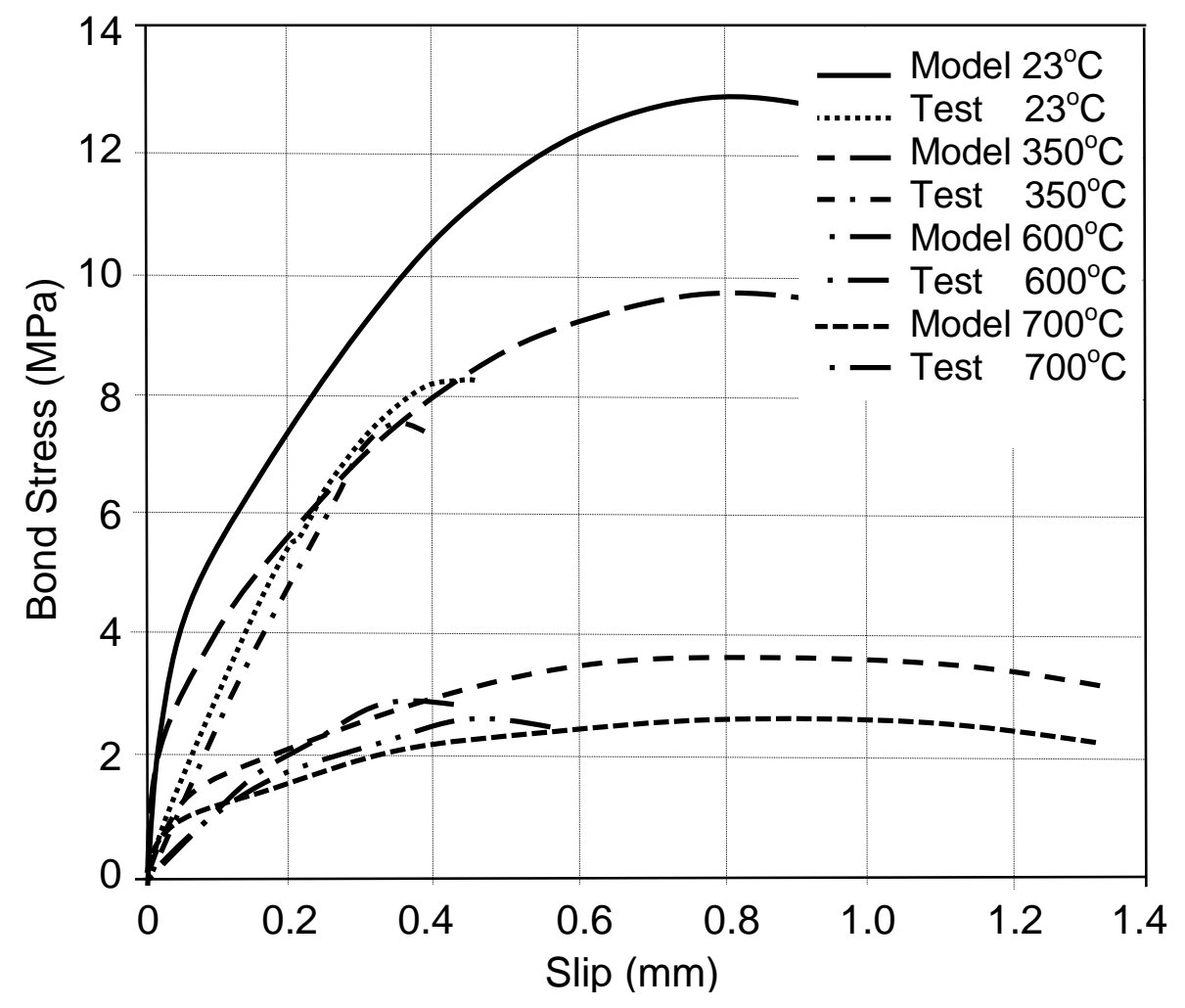

(e) Tested by Haddad et al. [27]

Fig. 10 Comparison of predicted and measured bond stress-slip curves at elevated temperatures

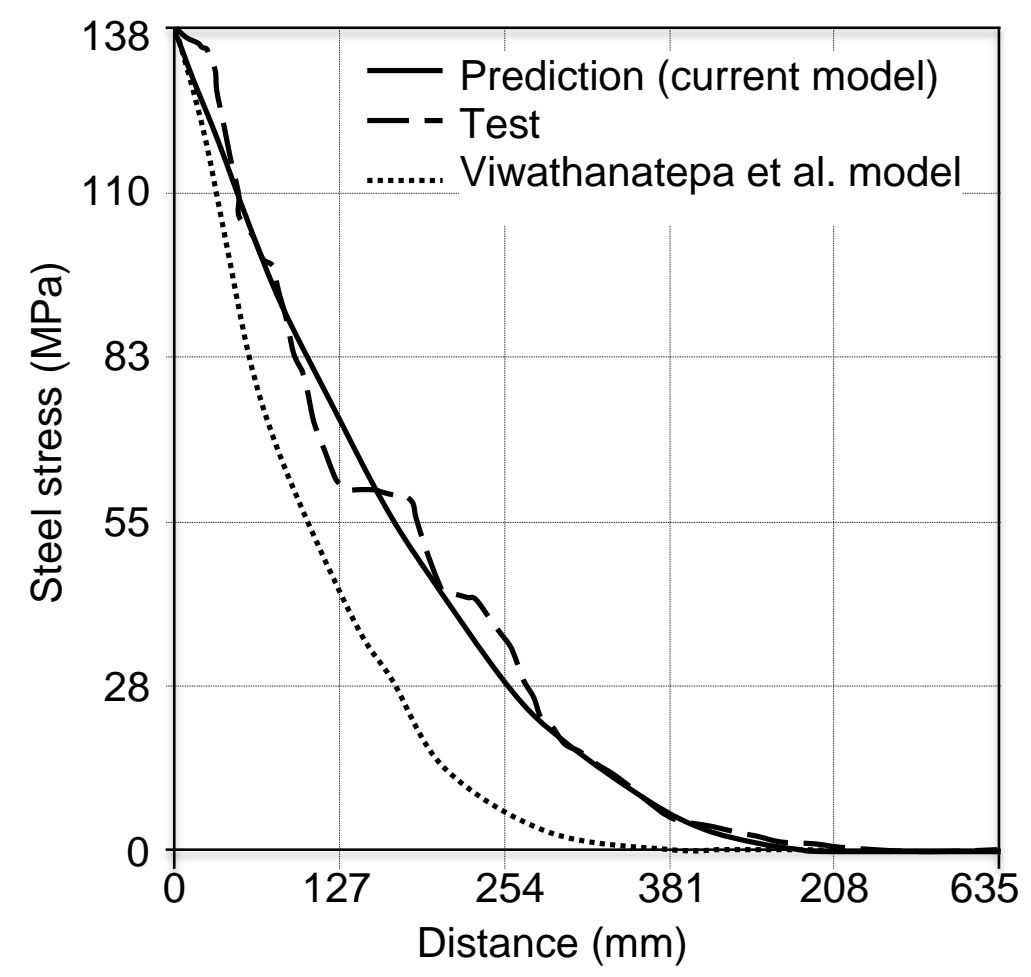

(a) End stress=138 MPa 


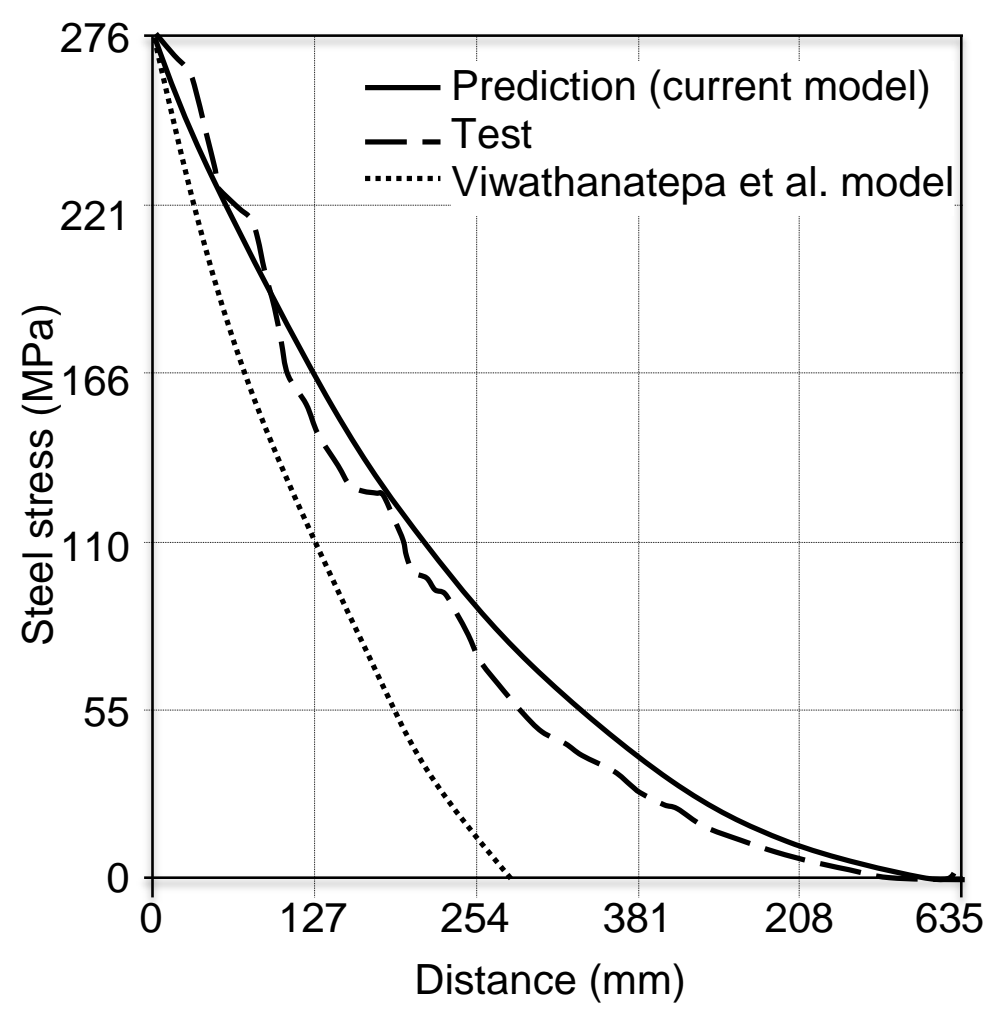

(b) End stress=276 $\mathrm{MPa}$

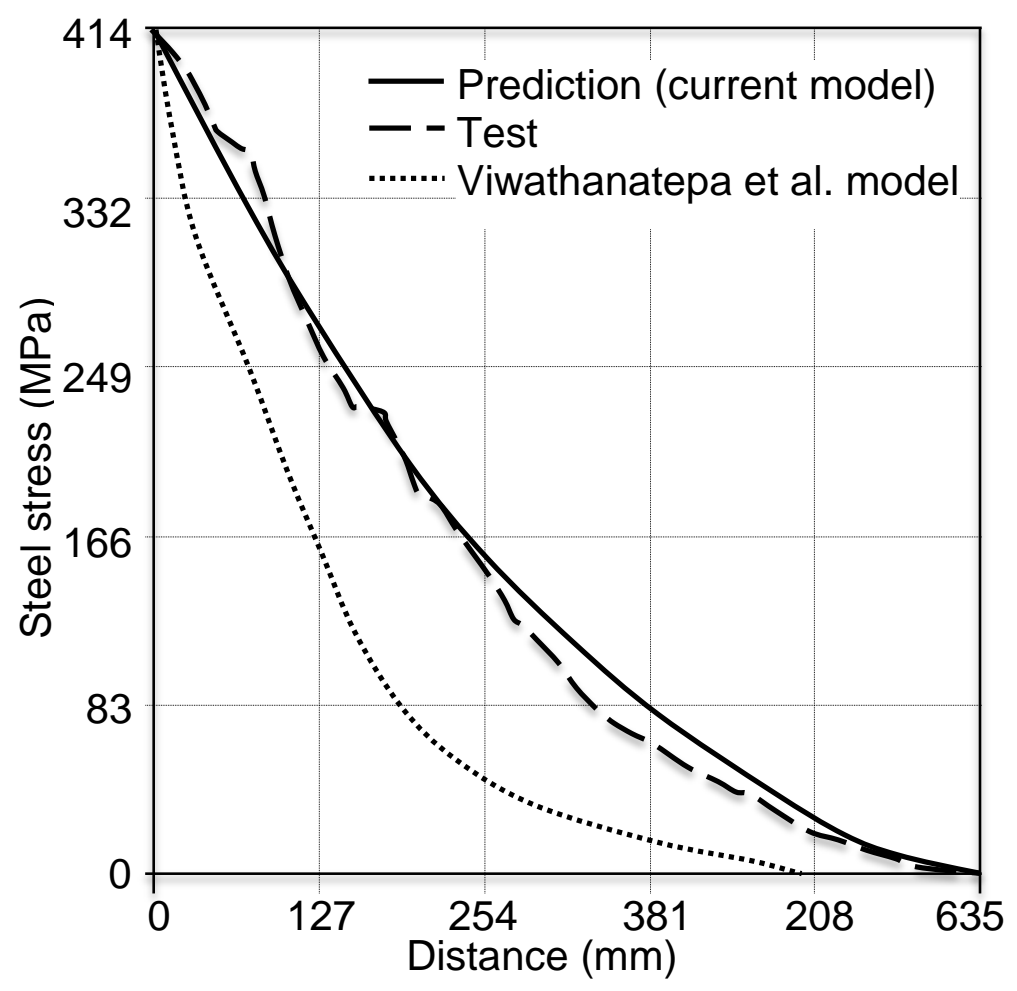

(c) End stress=414 $\mathrm{MPa}$

Fig. 11 Comparison between the predicted and tested stress distributions along anchored reinforcing steel bar [8] 


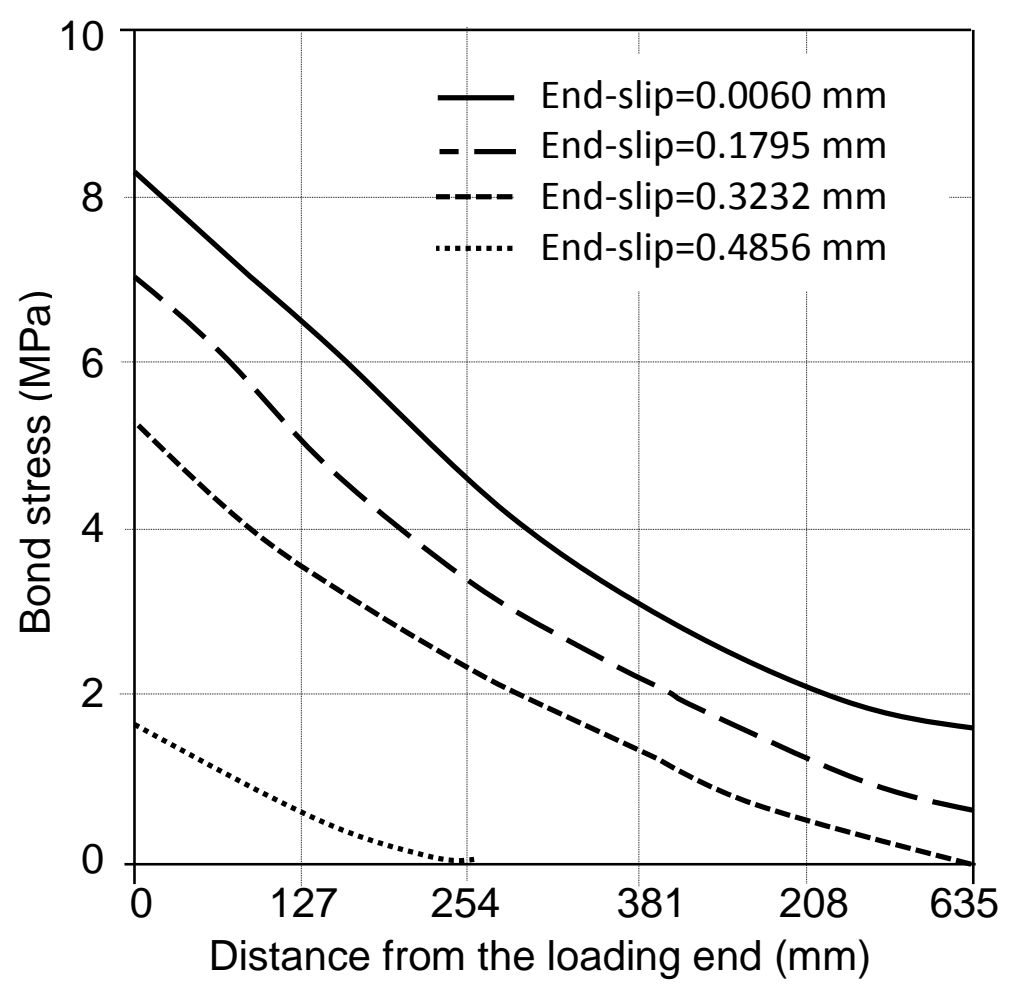

Fig. 12 Predicted bond stress distributions corresponding to different end-slips for test [8]

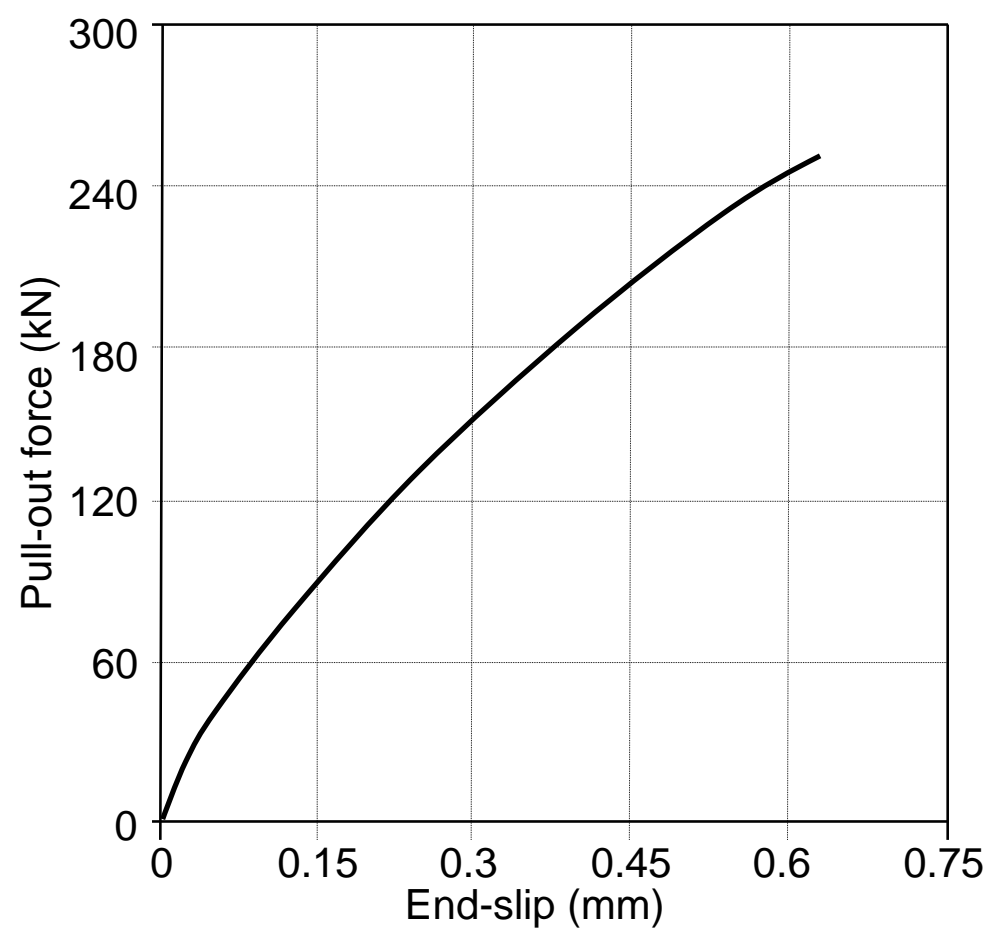

Fig. 13 Predicted end-slips vs pull-out force for the test [8] 


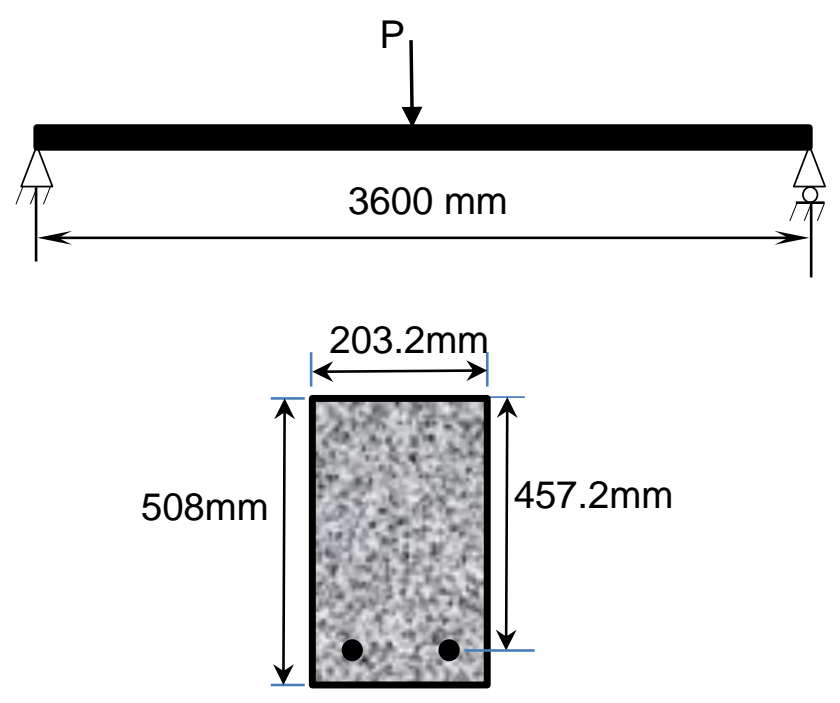

Fig. 14 Details of J4 beam tested at ambient temperature [28]

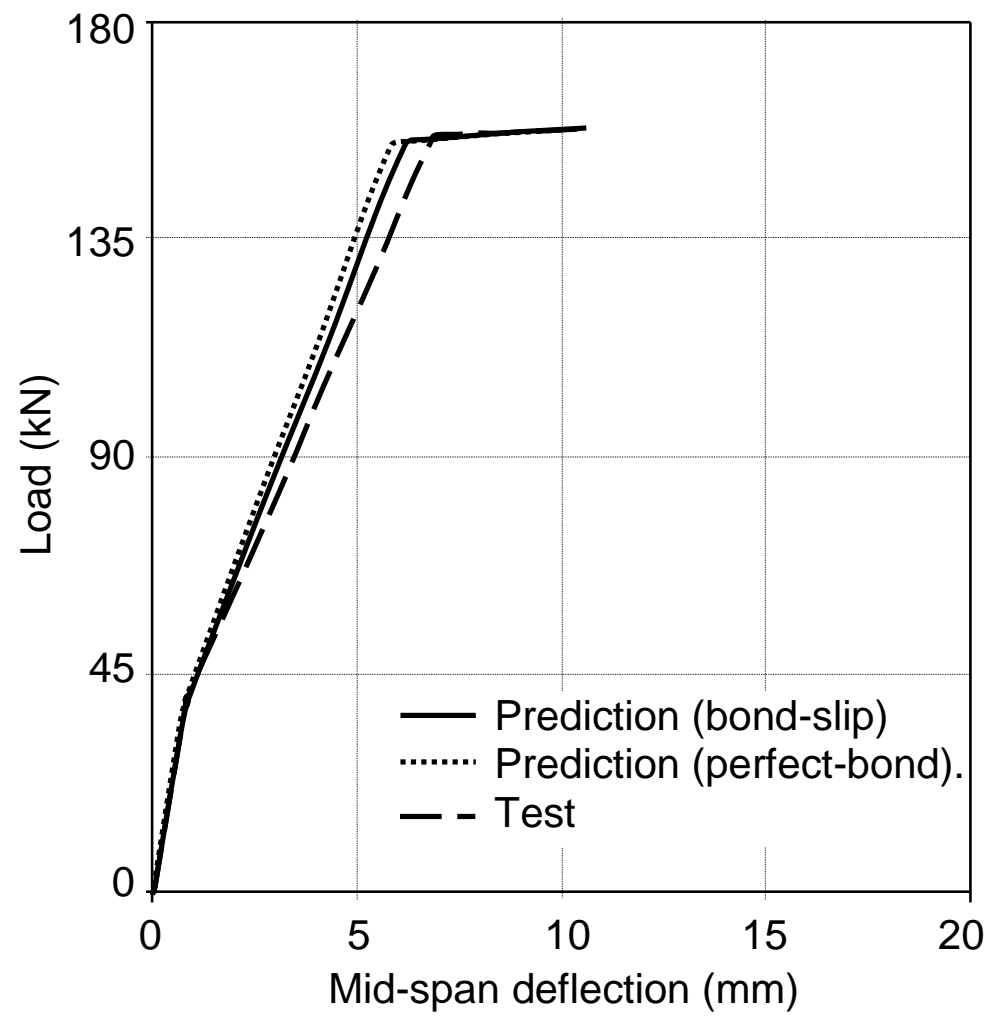

Fig. 15 Comparison of predicted and measured mid-span deflections of J4 beam [28] 


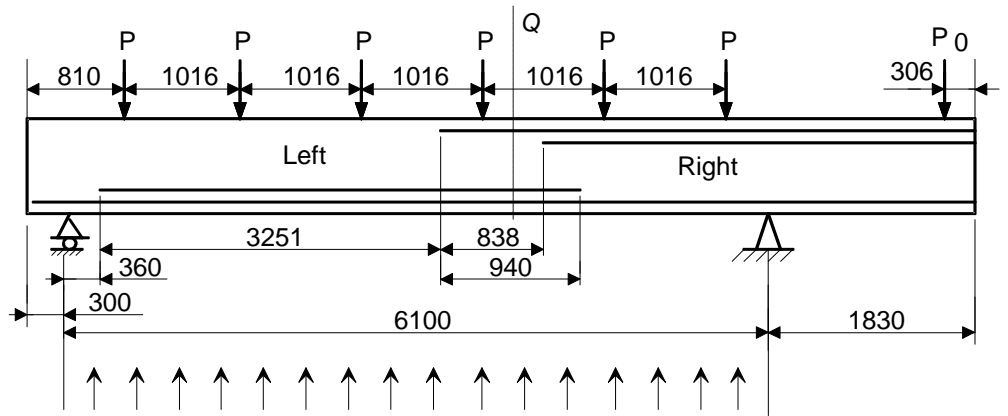

Surface exposure to fire conditions

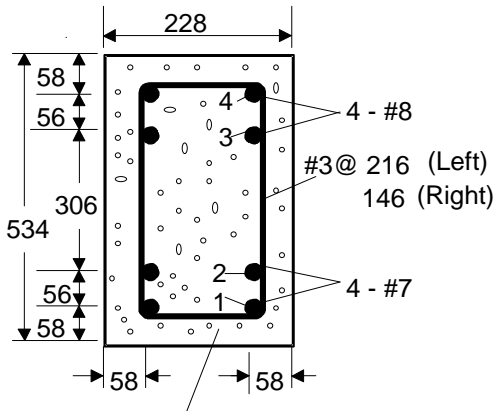

Beam No. 1, 5

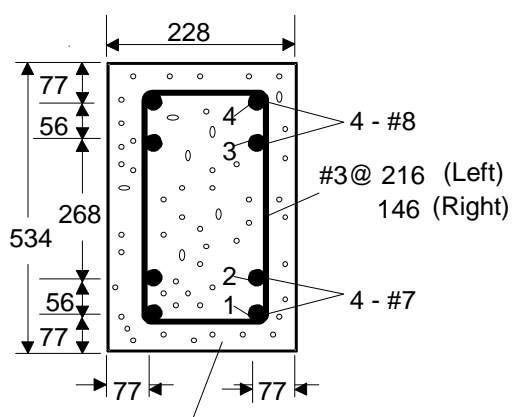

Beams No. 3, 6

All dimensions in $\mathrm{mm}$

Fig. 16 Details of tested beams in fire [29]

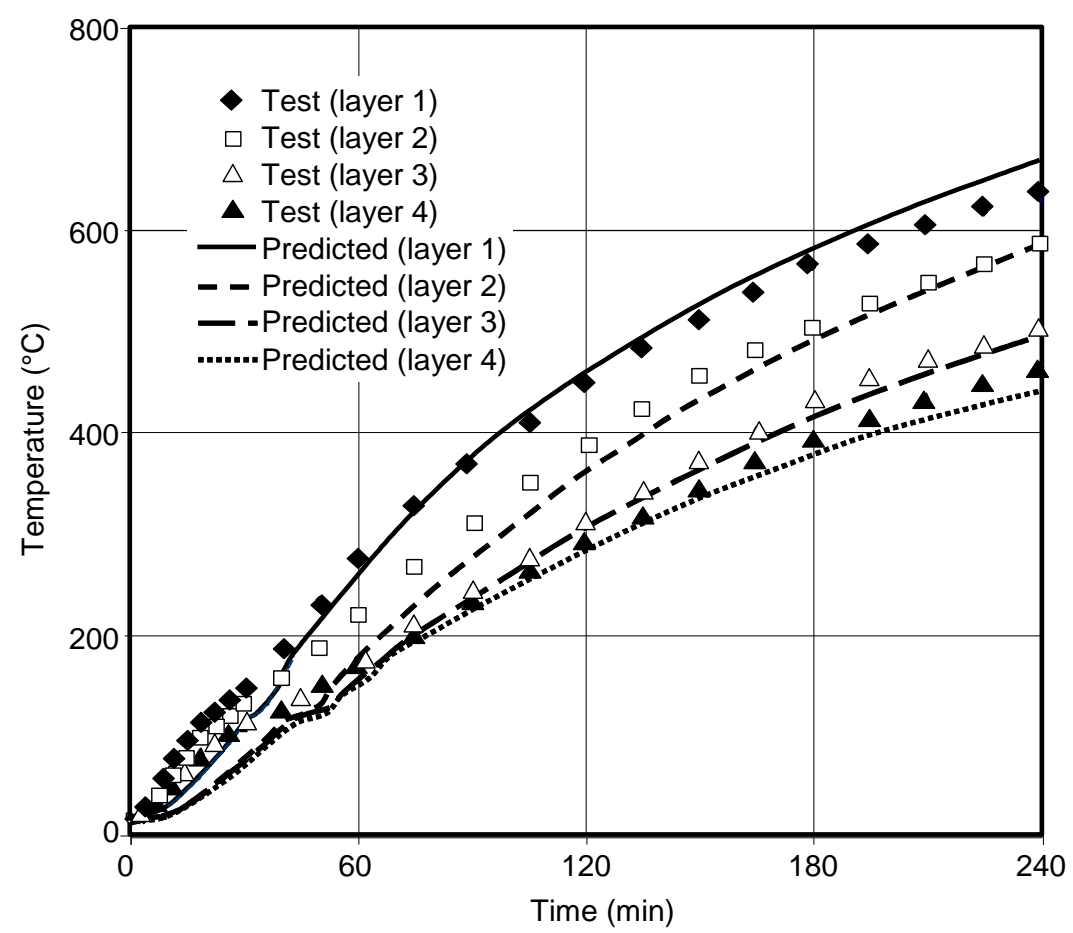

Fig. 17 Comparison of predicted and measured temperatures of four main reinforcing steel layers for Beam 1 [29] 


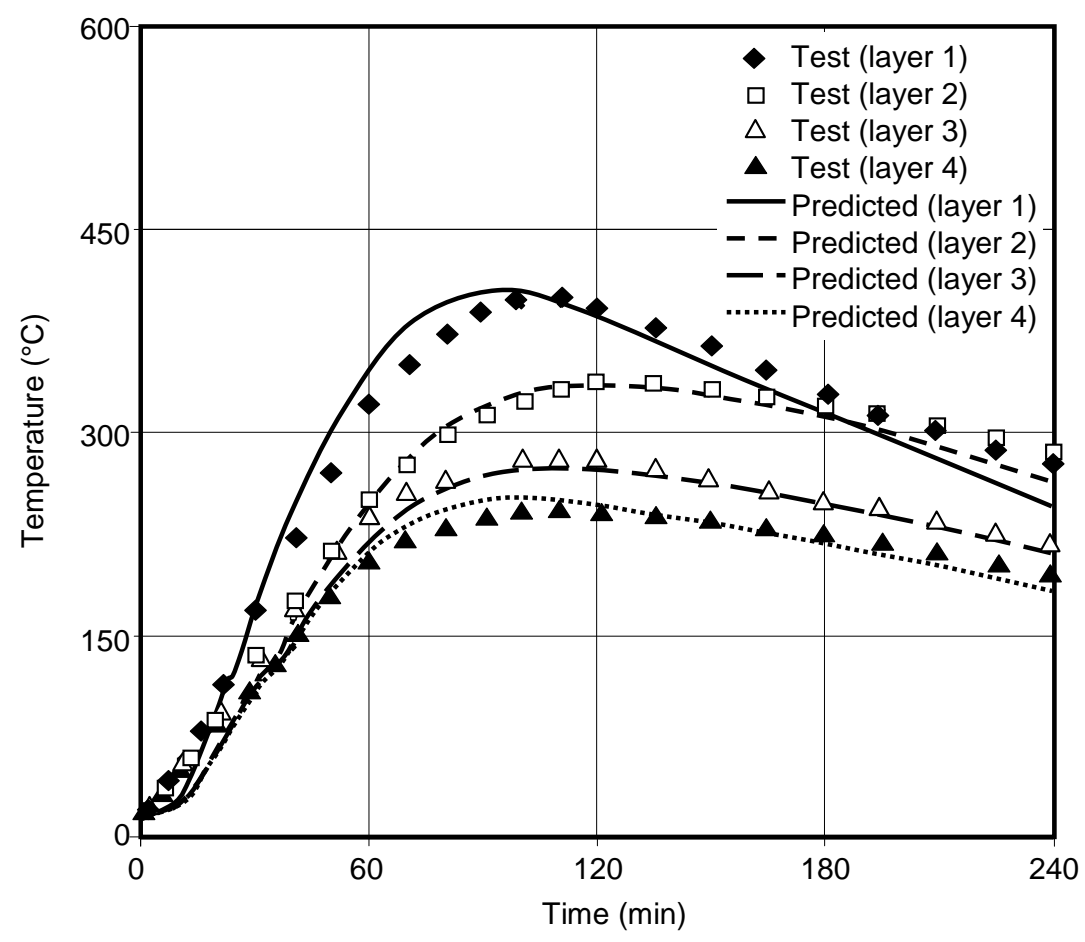

Fig. 18 Comparison of predicted and measured temperatures of four main reinforcing steel layers for Beam 5 [29]

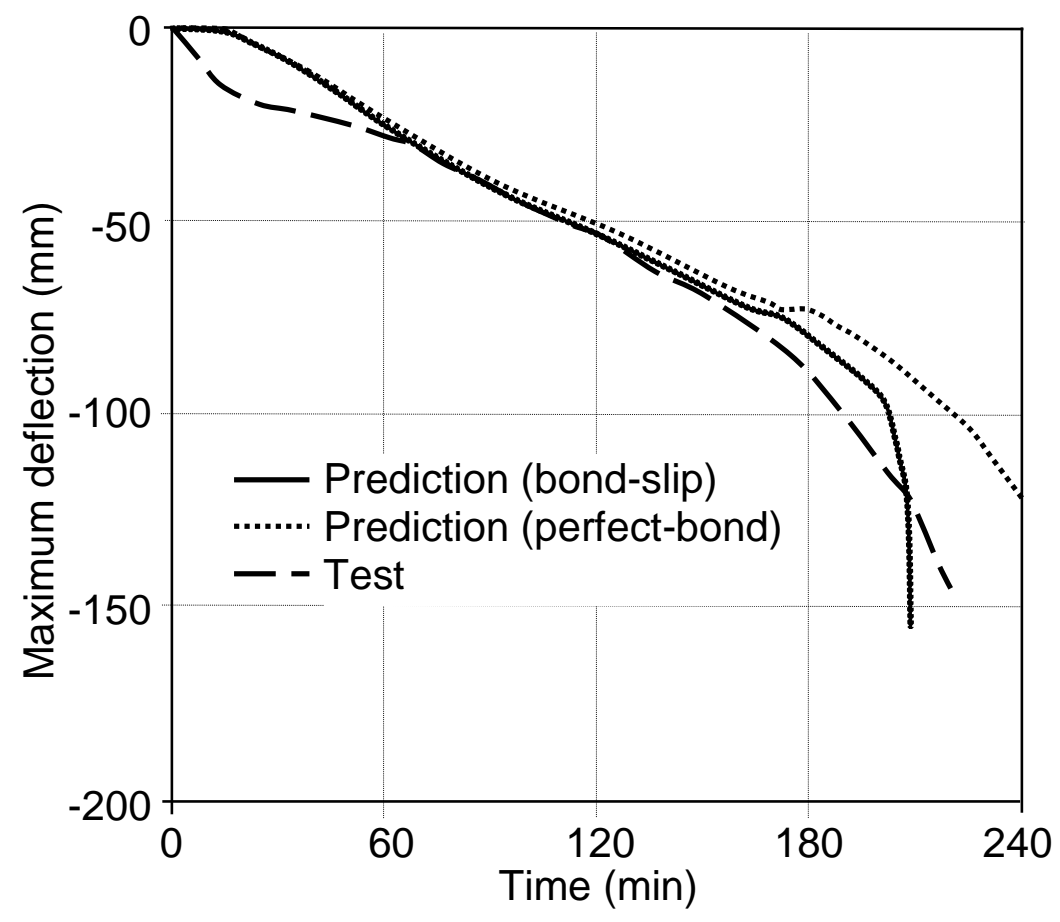

Fig. 19 Comparison of predicted and measured maximum deflections of Beam1 (ASTM Fire) [29] 


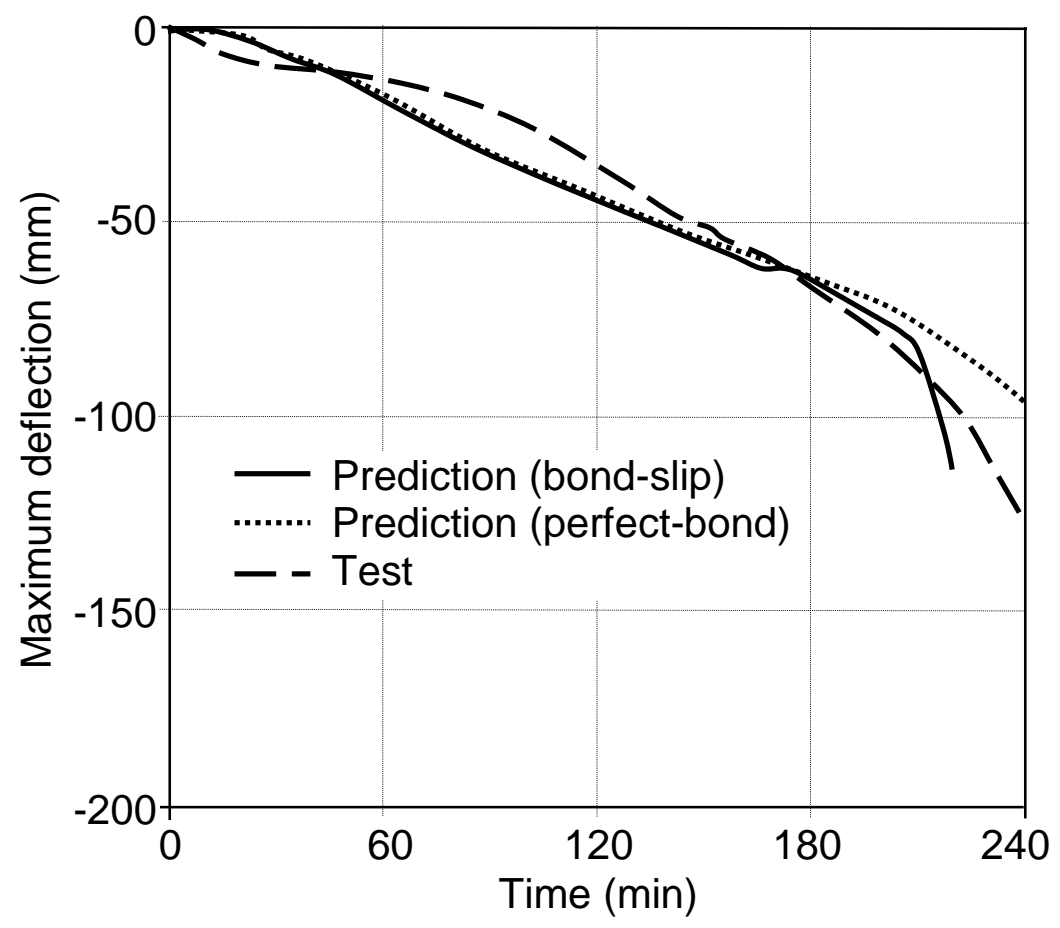

Fig. 20 Comparison of predicted and measured maximum deflections of Beam3 (ASTM Fire) [29]

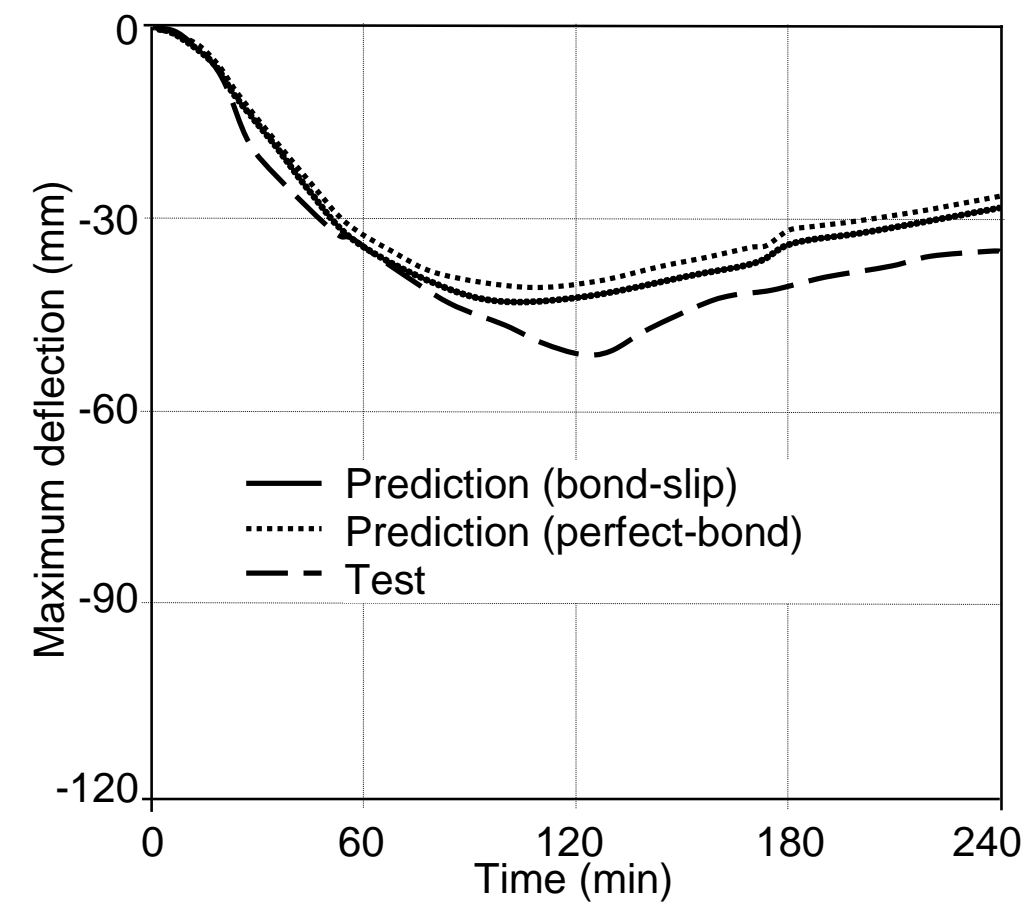

Fig. 21 Comparison of predicted and measured maximum deflections of Beam5 (SDHI Fire) [29] 


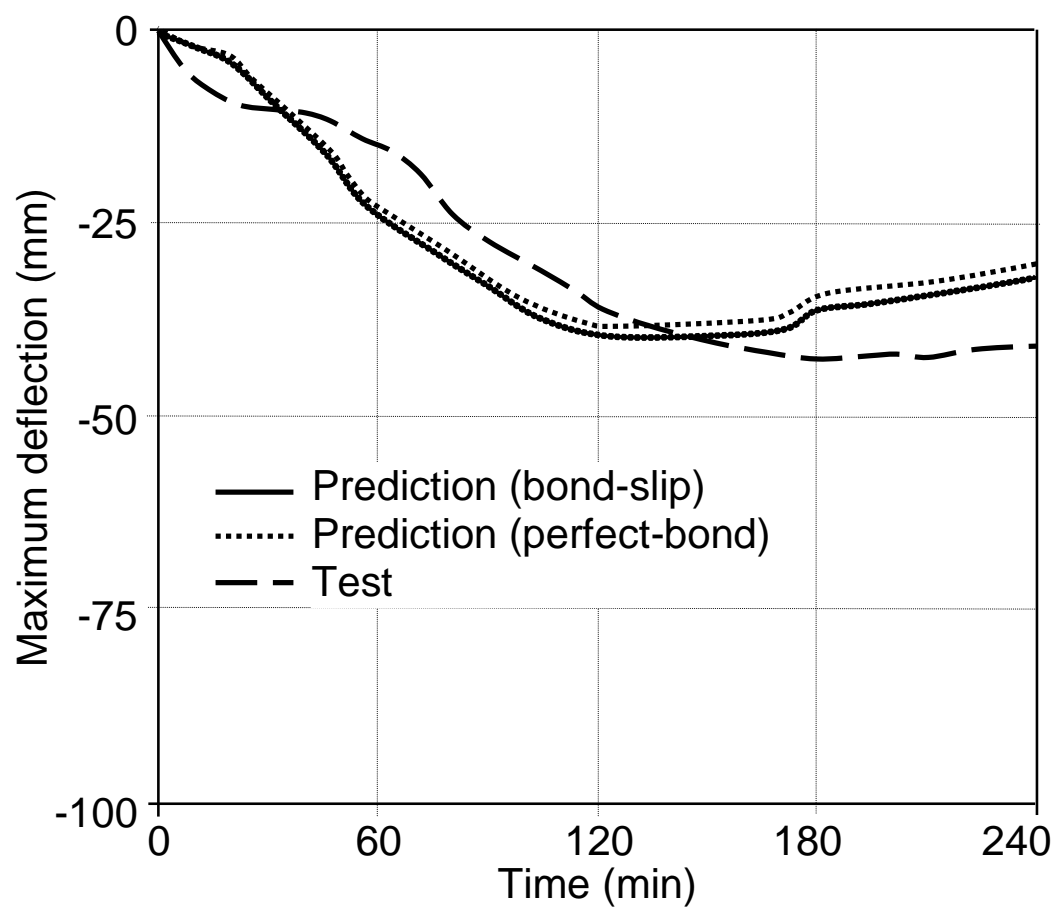

Fig. 22 Comparison of predicted and measured maximum deflections of Beam6 (SDHI Fire) [29] 